\title{
Cognition in Organizations
}

\author{
Gerard P. Hodgkinson and Mark P. Healey
}

Leeds University Business School, University of Leeds, Leeds LS2 9JT,

United Kingdom; email: gph@lubs.leeds.ac.uk, busmph@leeds.ac.uk

Annu. Rev. Psychol. 2008. 59:387-417

First published online as a Review in Advance on June 4, 2007

The Annual Review of Psychology is online at http://psych.annualreviews.org

This article's doi:

10.1146/annurev.psych.59.103006.093612

Copyright (c) 2008 by Annual Reviews. All rights reserved

0066-4308/08/0203-0387\$20.00

\section{Key Words}

managerial and organizational cognition, organizational behavior, information processing, decision making, cognitive engineering, shared cognition

\begin{abstract}
This article reviews major developments from 2000 to early 2007 in the psychological analysis of cognition in organizations. Our review, the first in this series to survey cognitive theory and research spanning the entire field of industrial and organizational psychology, considers theoretical, empirical, and methodological advances across 10 substantive domains of application. Two major traditions, the human factors and organizational traditions, have dominated cognitively oriented research in this field. Our central message is that the technological and human systems underpinning contemporary organizational forms are evolving in ways that demand greater cooperation among researchers across both traditions. Such cooperation is necessary in order to gain theoretical insights of sufficient depth and complexity to refine the explanation and prediction of behavior in organizations and derive psychologically sound solutions to the unprecedented information-processing burdens confronting the twenty-first century workforce.
\end{abstract}




\section{Contents}

INTRODUCTION.............. 388

HISTORICAL BACKGROUND

AND THEORETICAL

FOUNDATIONS ............. 389

The Human Factors Tradition .... 389

The Organizational Tradition .... 389

Computation and Interpretation:

Metaphors Bridging the

Traditions................ 391

SUBSTANTIVE DOMAINS OF

APPLICATION .............. 391

Personnel Selection and

Assessment................. 391

Work Groups and Teams ........ 392

Training and Development....... 394

Stress and Occupational Health . . 395

Work Motivation ............... 395

Work Design and Cognitive

Ergonomics .............. 396

Leadership ................. 397

Organizational Decision Making . . 398

Organizational Change and

Development .............. 399

Individual Differences ........... 401

METHODOLOGICAL

DEVELOPMENTS ........... 402

FUTURE CHALLENGES ........ 403

Crossing the Traditions .......... 403

Crossing the Domains ........... 404

Integrative Understanding Within

Domains.................. 404

The Challenge of Emotion ....... 404

Laboratory Versus Field .......... 405

CONCLUSIONS.............. 405

\section{INTRODUCTION}

The study of cognition in organizations has been on the ascendancy for the past two decades. This should come as no surprise, for the vast scale of political, economic, social, and technological change confronting modern organizations is placing unprecedented information-processing burdens on the individuals and groups working within them. Ac- cordingly, there has been a dramatic growth in psychological research directed toward advancing understanding of the cognitive capabilities and limitations of managers and employees, with a view to enhancing productivity and well-being in the workplace.

Our article is the first in the Annual Review of Psychology to cover advances in cognitive theory and research across the industrial and organizational (I/O) psychology field as a whole. Hence, we commence with a brief overview of historical developments, including the principal theoretical advances in cognitive psychology and social cognition that have informed the contemporary cognitive analysis of behavior in organizations. We then survey key developments across 10 major substantive domains of I/O psychology, namely, personnel selection and assessment, work groups and teams, training and development, stress and occupational health, work motivation, work design and cognitive ergonomics, leadership, organizational decision making, organizational change and development, and individual differences. Finally, we review recent methodological advances and highlight future directions for the field as a whole.

For the purposes of this review, it is useful to conceive of psychological research on cognition in organizations as falling into two major traditions: (a) the human factors tradition, and $(b)$ the organizational tradition. Research in both traditions has important implications for the design of tasks, jobs, and new organizational forms, and for enriching the understanding of behavior both within and between organizations. As our review demonstrates, there are clear signs that in recent years human factors and organizational researchers have begun to cooperate across these traditions. Our overarching conclusion, however, is that such is the scale of the changes that have occurred in the world of work over recent decades that greater cooperation is now required in order to advance theoretical understanding of sufficient sophistication to inform the development of psychologically 
sound solutions to the increasingly complex challenges confronting the contemporary workforce.

\section{HISTORICAL BACKGROUND AND THEORETICAL FOUNDATIONS}

The purpose of this section is to outline, albeit briefly, the history of work on cognition in organizations, from its inception to the outset of the current review period, in order to provide the necessary background to inform a coherent and integrated review of contemporary developments across the 10 main domains of application.

\section{The Human Factors Tradition}

The human factors tradition subsumes the fields of engineering psychology and human performance, including psychological aspects of ergonomics, which blossomed as behaviorism gave way to cognitivism. The human information-processing approach to the analysis of skilled performance rose to prominence toward the end of the Second World War. Researchers attempted to refine understanding of the perceptual-motor tasks that predominated work in heavy industry at that time through the detailed analysis and modeling of the human-machine interface. Drawing on the computational metaphor that then predominated in cognitive experimental psychology, researchers in this tradition conceptualized the execution of skilled performance as a stage-based sequence of functions, including sensory and perceptual processes, memory, and decision making, culminating in the execution of skilled responses (see, e.g., Broadbent 1958).

As organizational technologies evolved, researchers turned to investigate more directly human operators' mental representations of complex industrial processes and systems in order to explore their nature and impact on system performance (see, e.g., Edwards \& Lees 1974). Following Card et al.'s (1983) seminal volume, the so-called knobs and dials era gave way to the era of humancomputer interaction, informing the design of computer-based systems, from basic desktop machines to modern-day flight decks. Although the mental models concept, coined initially by Craik (1943), continues to play a central role in this more recent work, it has been the subject of increasingly critical scrutiny amid debates concerning its definition and usage, ranging from conceptions as temporary dynamic models in working memory, in similar vein to Johnson-Laird's (1983) notion of mental models, to enduring knowledge structures in long-term memory, akin to Bartlett's (1932) notion of schema (see Rouse \& Morris 1986).

As observed by Wickens \& Carswell (2006), in addition to the staged-based approach enumerated above, two other approaches to human information processing currently prevail within the human factors tradition. The first, known as the ecological approach, emphasizes human interaction with the environment and is characterized by the study of expertise in naturalistic settings. The second, the cognitive engineering approach, constitutes a hybrid approach bringing together key elements of the stage-based and ecological approaches, in an attempt to further understanding of the interactions between task and environmental constraints and operators' knowledge structures. Human factors researchers adopting the cognitive engineering approach (e.g., Zhang \& Norman 1994) are beginning to examine the role of complex workplace technology as both a shaper and repository of knowledge (see also Hutchins 1995), a trend paralleled in the organizational tradition (cf. Walsh \& Ungson 1991). Salvendy (2006) provides extensive coverage of work in the human factors tradition from its inception up to the current review period.

\section{The Organizational Tradition}

Theory and research within this tradition have gathered momentum over the past two 
decades. Its origins, however, can be traced to Simon's (1947) Administrative Behavior, in which he outlined the notion of bounded rationality, the idea that organizational decision makers strive for rationality within the limits of their cognitive capacities and information availability (see also March \& Simon 1958). However, Weick (1979) subsequently called into question several of the core assumptions underpinning the bounded rationality notion through his work on enactment and the related concept of sensemaking. In particular, he challenged the idea that the environment is an objective entity that can only be partially comprehended due to limited processing capacity. On the contrary, he maintained that decision makers literally create their own constraints through an active constructive process, in which they rearrange, isolate, and demolish seemingly objective features of their surroundings, in turn giving rise to subjective differences in perception.

Hambrick \& Mason's (1984) upper echelons perspective added further impetus to the organizational tradition. Drawing on Simon's notion of bounded rationality, this approach views strategic choice as a function of the demographic and psychological composition of the organization's top management team. Because of the difficulties of studying the mental representations and other psychological characteristics of the organization's executive team members in situ, Hambrick \& Mason (1984) advocated indirect methods of cognitive assessment, whereby executives' background characteristics (e.g., education, functional specialization) are used as proxies for cognitive variables (i.e., values and beliefs) in the prediction of organizational outcomes (e.g., firm performance). From the early 1990s onward, the upper echelon approach has been the subject of growing theoretical and empirical scrutiny amid numerous contradictory and inconsistent findings. Responding to these challenges, more recent work has incorporated direct methods of cognitive assessment, thereby isolating the determinants and consequences of executive perceptions and beliefs (e.g., Chattopadhyay et al. 1999, Markoczy 1997).

The development of direct methods to probe more deeply organizational decision makers' mental representations gathered pace throughout the 1990s, following the publication of Huff's (1990) influential volume and Walsh's (1995) landmark review, together with several special issues of key management and organization studies journals (e.g., Fournal of Management Studies, Organization Science). Inter alia this body of work has enriched understanding of the nature and role of mental representations in both organizational inertia and strategic adaptation (e.g., Kiesler \& Sproull 1982, Porac et al. 1995). However, as with the human factors tradition, construct validity issues and the proliferation and inconsistent use of terms and concepts relating to the mental representations notion have made conceptual integration and theoretical progression difficult.

Meanwhile, attribution theory (Kelley 1967) has enriched understanding in a range of substantive domains of application, from the analysis of personnel selection decisions to the investigation of managers' explanations of employee and organizational performance. Following Ashforth \& Mael (1989), social identity theory (Tajfel \& Turner 1979) and related conceptions of self- and socialcategorization have similarly influenced research across a wide range of topics, from cooperation in the workplace to socio-cognitive processes in strategic management. Further work in social cognition emphasizing the tendency of individuals to seek consistency in their attitudes and beliefs (e.g., Heider 1958) has also been foundational in the development of several cognitive theories of work motivation, not least equity theory and related formulations (e.g., justice theory). Finally, various heuristics and biases elucidated by behavioral decision researchers (e.g., Tversky \& Kahneman 1974) have been shown to influence judgment and choice in a range of personnel and organizational decision processes. The study of heuristic and intuitive processing 
has received added impetus over recent years (for a review, see Hodgkinson et al. 2008), following an explosion of interest in dual-process theories of cognition in cognitive psychology (e.g., Gilovich et al. 2002) and social cognition (e.g., Chaiken \& Trope 1999). For further background and a detailed overview of the origins of the organizational tradition, see Walsh (1995) and Hodgkinson \& Sparrow (2002).

\section{Computation and Interpretation: Metaphors Bridging the Traditions}

In sum, five major theoretical perspectives drawn from cognitive experimental psychology and social cognition pervade contemporary research on cognition in organizations, namely (a) schema theory and related conceptions of mental representations (especially the notion of mental models), (b) behavioral decision theory (especially work on heuristics and biases), ( $c$ ) attribution theory, $(d)$ social identity theory and related conceptions ${ }^{1}$, and (e) enactment and the related notion of sensemaking. ${ }^{2}$ To a greater or lesser extent, each perspective has shaped the direction of work within and across the human factors and organizational traditions.

It is helpful at this juncture to borrow Lant \& Shapira's (2001) distinction between the computational and interpretive perspectives on cognition in organizations. The former, exemplified by the work on mental representations and behavioral decision research, draws attention to the fundamental information-processing limitations of orga-

\footnotetext{
${ }^{1}$ Many writers employ the term social identity theory, where strictly speaking the social identity approach is a more appropriate term. The latter comprises a combination of social identity theory and self/social categorization theory and thus constitutes an approach, rather than a theory as such (see Haslam 2001).

${ }^{2}$ The social cognitive theory of Bandura and colleagues is yet another highly influential approach that has contributed to the development of work on cognition in organizations, highlighting the interaction between personal goals, cognition, and environmental factors in the regulation of motivated behavior, encapsulated in the notion of self-efficacy (see, e.g., Bandura 1977, Wood \& Bandura 1989).
}

nizational decision makers and the strategies they employ in an effort to overcome those limitations, thus emphasizing the downstream choice or calculation processes at the heart of decision making and problem solving. The latter, in contrast, exemplified by Weick's work, emphasizes the upstream processes of sensemaking used by individuals and groups to extract patterns of meaning from ambiguous environmental cues in the social construction of organizational realities. As demonstrated above and in the remaining sections of this article, these processes coexist in a dynamic interplay.

\section{SUBSTANTIVE DOMAINS OF APPLICATION}

In the following sections, we survey developments within the current review period across the 10 substantive domains. The terrain is vast. Accordingly, our review does not purport to be comprehensive. Rather, we focus on what we consider the pivotal advances informed by each of the five dominant theoretical perspectives and related formulations outlined above.

\section{Personnel Selection and Assessment}

Building on earlier work that adopted a social and political, as opposed to a psychometric, perspective on personnel selection and assessment (e.g., Cleveland \& Murphy 1992, Herriot 1989), researchers have continued to explore the fundamental attributional processes influencing assessor judgments of candidates (Nemanick \& Clark 2002, Silvester et al. 2002). However, there has been a shift of emphasis toward the analysis of candidates' reactions to the selection and assessment process, informed by justice-theoretic perspectives (Hausknecht et al. 2004, Ryan \& Ployhart 2000), including the identification of antecedents of justice perceptions (Shaw et al. 2003, Truxillo et al. 2002) and an exploration of the effects of justice expectations on 
applicants' reactions to the selection process (e.g., Bell et al. 2006).

Ployhart \& Harold's (2004) Applicant Attribution-Reaction Theory views candidates' attributions of the causes of their experience of the selection process as the critical determinant of their affective, cognitive, and behavioral reactions, including their justice perceptions. Although potentially insightful, this theory has yet to be evaluated empirically and further work seeking to demonstrate the incremental gains in the prediction of candidate reactions through the integration of justice theory with attribution theory is now urgently required. In the meantime, however, Herriot (2004) has developed an alternative account of applicants' reactions, with a view to predicting their intention to exit the selection process, based on social identity theory. As with the Ployhart \& Harold (2004) formulation, empirical work directed to the testing of this theory is now a priority. Meanwhile, social identity theory has also been used to explain the effects of demographic (dis)similarity between job candidates and assessors on selection decisions (Goldberg 2005).

A longstanding problem in the design of assessment and development centers concerns the lack of consistent behavioral ratings across exercises designed to tap common constructs. Interactionist models of behavior underpinned by social cognitive views of personality have been used in recent years to explain such inconsistencies, which are seen as a function of candidates responding differentially to the diversity of situational cues afforded by the various assessment tasks (e.g., Lievens et al. 2006). Work on the malleability of personal attributes has also been extended to the role of the performance appraiser. Heslin et al. (2005), for example, showed that appraisers who believe that personal attributes are relatively fixed are less likely to acknowledge changes in appraisees' behavior over time than those who believe these attributes are relatively changeable.

Although work continues on the cognitive mechanisms determining the accuracy of performance evaluations (e.g., Hennessey \& Bernardin 2003, London et al. 2004, Martell \& Evans 2005), it is clear that the appraisal process is being viewed increasingly in a wider socio-political context (Fletcher 2001). This has led some researchers to reconsider the implications of conventional work directed toward removing error and bias in rater judgments. Understanding divergence in performance assessments between parties requires an appreciation of their potentially disparate goals and motivations as well as the political processes operating within the wider organization.

It is important to emphasize that social constructionist perspectives do not negate the need for further work on rater cognitions. In the final analysis, rater judgments are central to the ongoing negotiated order that forms the basis of the psychological contract between employer and employee. Hence, the purpose of such work should be to develop insights that will assist all parties to the employment relationship to reach genuine agreement, a process foundational to the formation and maintenance of truly relational, as opposed to transactional, psychological contracts (cf. Rousseau 1995, Rynes et al. 2005). Recent applications of attribution theory and justice theory to the analysis of appraisers' and appraisees' perceptions of, and reactions to, the performance evaluation and reward allocation process (Johnson et al. 2002, Keeping \& Levy 2000, Schroth \& Shah 2000) stand to contribute to this richer agenda. Additional work that could also inform this agenda has examined the personal constructs underlying appraisers' and appraisees' perceptions of, and attitudes toward, performance evaluation systems (Wright 2004).

\section{Work Groups and Teams}

Interest in the cognitive basis of team functioning has increased dramatically. Fortunately, however, Ilgen et al. (2005) recently surveyed a number of the key developments arising from this work. Hence, we only 
consider major developments beyond the scope of their review.

Following Cannon-Bowers \& Salas (2001), work on the conceptual refinement, measurement, and empirical analysis of shared cognition has gained momentum. For example, recent studies have differentiated task-specific knowledge from team process knowledge, finding that each form yields benefits in terms of team processes and task performance (e.g., Lim \& Klein 2006, Mathieu et al. 2000). The notion of shared cognition has been defined variously (e.g., overlapping, complementary, distributed) amid growing recognition that the optimal form of sharing is contingent upon the nature of the task and situational variables (e.g., Ren et al. 2006), and varies as task demands evolve over time (Levesque et al. 2001). Cooke et al. (2000) and Langan-Fox et al. (2000) extensively reviewed developments in the measurement of shared cognition. Subsequently, researchers have advanced increasingly sophisticated metrics, distinguishing within-team sharing of mental models from the accuracy of such models relative to those of experts (e.g., Mathieu et al. 2005). In addition, Austin (2003) has developed a multidimensional instrument for assessing the transactive memory construct, i.e., knowing where to find particular expertise within the team. Doubtless, these advances will help inform emerging work exploring the antecedents (Brandon \& Hollingshead 2004, Bunderson 2003) and consequences of transactive memory (Faraj \& Sproull 2000), and shared cognition more generally (e.g., Rentsch \& Klimoski 2001).

Increasingly, modern work practices involve the collaborative efforts of multiple teams, often drawn together temporarily from diverse organizations, as for example when teams drawn from multiple agencies come together in emergency and crisis situations. Mathieu et al. (2001) have proposed the concept of multiteam systems (MTSs) to address the information-processing problems arising in these "teams of teams." They extend work on the shared mental models posited to operate within conventional teams (e.g., task, team process), reviewed above, to encapsulate the varieties of knowledge structure required so that component teams within MTSs readily comprehend one another's purposes, resource capabilities, and limitations and requirements in order to respond effectively to shifting environmental contingencies. Elements of the MTSs notion have recently been tested in laboratory settings (DeChurch \& Marks 2006, Marks et al. 2005), but its overall utility has yet to be scrutinized empirically in the field.

Given the concomitant increases in the pace of organizational change and allocation of work tasks to team units, researchers have continued to explore the cognitive bases of team adaptation, including team cognitive ability composition (LePine 2003). Burke et al. (2006) recently developed a multilevel conceptual model that brings together the individual cognitions (e.g., knowledge, cognitive ability, team orientation) and group cognitions (e.g., team situation awareness, shared mental models) that underpin team adaptation over time.

Notwithstanding the scale of criticisms leveled against the upper echelons approach and recent advances in the direct assessment of team cognition, a surprising number of studies within the current review period have merely sought to extend further this approach, using basic background variables as a proxy for cognitive and related psychological processes (e.g., Carpenter 2002, Herrmann \& Datta 2006). Over the longer term, studies incorporating direct methods of cognitive assessment (e.g., Kilduff et al. 2000, Markoczy 2001) will surely lead to richer understanding of top management team processes and outcomes than those studies based on proxy measures. This is not to rule out the use of background characteristics in the analysis of cognitive processes in organizations. Indeed, a sizable volume of work informed by the social identity approach has postulated a central role for demographic variables in the processing of information by work groups and teams,
MTSs: multiteam system 
as reviewed by van Knippenberg \& Schippers (2007).

\section{Training and Development}

Ford \& Kraiger (1995) revisited the foundational instructional systems framework (the origins of which lie in behaviorism) in order to map out a comprehensive agenda for organizational training and development from a cognitive perspective (see also Kraiger et al. 1993). Viewed from such a perspective, the central questions in respect of individual and team level training become how to impart, develop, and/or change trainees' knowledge structures (i.e., their mental models/schemata), not only to equip them to perform immediate day-to-day tasks, but also expand their repertoires for dealing with uncertainties in the wider transfer environment (see also Salas \& Cannon-Bowers 2001).

At the individual level within the current review period, researchers have continued to investigate the potential of a range of interventions to enrich the content and/or structure of trainees' task-specific knowledge structures as an outcome of training, both in the laboratory (e.g., Bell \& Kozlowski 2002, Kozlowski et al. 2001, Sauer et al. 2000, Schmidt \& Ford 2003) and to a lesser extent in the field (e.g., Brown 2001, Ellis \& Davidi 2005). The interventions investigated have included the provision of adaptive guidance (Bell \& Kozlowski 2002) and the relative efficacy of rule- and systembased learning (Sauer et al. 2000). The conceptualization of knowledge-based training outcomes is becoming increasingly sophisticated; for example, researchers have begun to distinguish between procedural and declarative knowledge developed through training (e.g., Sitzmann et al. 2006). Unfortunately, however, based on differing conceptions, researchers have employed a diversity of methods to operationalize the notion of knowledge structures across studies spanning multiple knowledge domains. Content mea- sures have included direct measures of declarative knowledge via questionnaires (e.g., Schmidt \& Ford 2003) and the analysis of verbal protocols (Sauer et al. 2000). Structural measures have included the formal mapping of perceived relationships among task-related concepts using, for example, the Pathfinder algorithm (Kozlowski et al. 2001, Marks et al. 2002) and causal cognitive mapping techniques (Ellis \& Davidi 2005). The domains investigated have been equally diverse, ranging from surgery (Arnold \& Farrell 2002) to military navigation (Ellis \& Davidi 2005). This basic confounding of research method with knowledge domain is impeding the development of cumulative insights. Hence, a program of work directed toward establishing the convergent and discriminant validity of the various measures in use for the assessment of the structure and content of trainees' knowledge structures, and the validation of a broader nomological network encompassing cognitive training outcomes, continues to be badly needed (cf. Kraiger et al. 1993).

At the team level within the current review period, substantial progress has been attained in the conceptualization and measurement of the team mental models construct as an outcome of training interventions such as cross-training (Marks et al. 2002) and computer-based training (Smith-Jentsch et al. 2001). These developments notwithstanding, the team mental models construct is still at an early stage of development and there are several outstanding issues concerning the application of this notion in the context of training and development. Specifically, it is unclear which variants of shared cognition (e.g., common, complementary, distributed knowledge) ultimately benefit the execution of various types of team task, or what training methods are best suited to the development of particular types of team mental model (e.g., task content related, team process related). Moreover, there is a pressing need for research to inform the design of interventions for imparting multiple variants of shared cognition and/or types of team mental model, with a view to 
maximizing positive transfer outcomes across the various component exercises.

\section{Stress and Occupational Health}

Work within this domain continues to be dominated by the measurement and modeling of social and physical factors as potential job stressors, accompanied by a recent proliferation of studies assessing the relative impact of individual difference variables and workplace characteristics on psychological and psychosomatic health (see Ferguson et al. 2006 for a meta-analysis of such studies). However, researchers have begun to open up the black box of stress appraisal and coping mechanisms (Lowe \& Bennett 2003, Troup \& Dewe 2002), thereby enriching earlier cognitive contributions to the understanding of workplace stress (Edwards 1992) and life stress more generally (e.g., Lazarus \& Folkman 1984). Based on the assertion that current approaches to the analysis of stress in the workplace are cognitively underspecified (cf. Dewe \& Cooper 2007), Daniels et al. (2004) proposed a model of stressor appraisal, coping choice, and affect predicated on several core cognitive principles (chiefly controlled and automatic processing, mental models, and inference by categorization). Several of the predictions of this relatively broad-based model have been supported empirically (e.g., Daniels et al. 2006). Related work of a more circumscribed nature has begun to explore in detail the nature and role of justice perceptions and related social comparison processes underpinning the experience of employee well-being, together with an analysis of the various situational and personal factors that trigger such judgments (Janssen 2004, Warr 2006). Another new line of inquiry, centered on the cognitive consequences of work-related stress, has begun examining the deleterious effects of stress on the formation and deployment of team mental models and transactive memory (Ellis 2006).

Research on job burnout within the current review period has also been informed by a variety of cognitively oriented perspectives. Maslach et al. (2001) have suggested that one prominent source of potential burnout arises from the "cognitive and emotional relationship" employees develop with their work and organizations. Specifically, violations of the psychological contract yield burnout because the erosion of a sense of reciprocity is inimical to the maintenance of employee well-being (Rousseau 1995). Drawing on the insights of attribution theory, Moore (2000) has offered an alternative conception in which the behavioral consequences of work-related emotional exhaustion (i.e., burnout) are mediated by employees' attributions of its causes. ${ }^{3} \mathrm{Nei}-$ ther of these conceptions, however, has been subjected to the rigors of empirical scrutiny. In a third cognitively oriented conception, Haslam \& Reicher (2006) demonstrated empirically that the social identity approach provides a potentially useful lens for analyzing the impact of intragroup processes as mediators of burnout and work-related stress more generally.

\section{Work Motivation}

Latham \& Pinder (2005) extensively reviewed developments in the major cognitively based work motivation theories, arguing that three theories predominate, namely, goal-setting, social cognitive, and organizational justice theories. In a related forward-looking commentary, Locke \& Latham (2004) called for greater integration of the dominant work motivation theories. There are encouraging signs that this is beginning to occur. Meyer et al. (2004), for example, outlined an integrative model of employee commitment and motivation, in which commitment is viewed as one of several forces that energize motivated behavior, building on the insights of goal

\footnotetext{
${ }^{3}$ Significantly, just outside of the current review period, Perrewe \& Zellars (1999) argued for the incorporation of attributional processes in the modeling of work stress appraisal, whereas others (Frese \& Zapf 1999, Schaubroeck 1999) maintained that studying the effects of "objective" environmental features is a more fruitful approach.
} 
setting theory, self-determination theory, ${ }^{4}$ and regulatory focus theory. In a second development, Steel \& Konig (2006) combined the insights of cumulative prospect theory and the notion of hyperbolic discounting from behavioral decision theory with classic expectancy theory and need theory formulations. Their temporal theory of motivation purports to refine the understanding and prediction of a wide range of work-related phenomena, from goal setting to job design and the behavior of groups and stock markets.

Additional efforts to advance work motivation theory beyond Latham \& Pinder's (2005) review include DeShon \& Gillespie's (2005) motivated action theory, which seeks to unify differing accounts of the goal orientation construct, and the combined social identity and self-categorization theory perspective offered by Ellemers et al. (2004). The latter provides an account of how identification with workplace collectives shapes the motivation of individuals and groups. Behind these latest developments lies a major dilemma for the wider field of work motivation as a whole; the proliferation of constructs with the introduction of each new formulation is undermining the quest for greater conceptual unity.

\section{Work Design and Cognitive Ergonomics}

As noted at the outset, viewed from a cognitive standpoint the new organizational forms and work practices emerging in response to globalization and related economic and political developments pose significant design challenges to I/O psychologists. One particular design challenge that continues to attract much research attention concerns the system

\footnotetext{
${ }^{4}$ Building on cognitive evaluation theory, selfdetermination theory has only recently been applied to the systematic analysis of work motivation (Gagne \& Deci 2005), although it has been widely applied in other domains. Self-determination theory models the interplay between extrinsic and intrinsic motivators and outlines the mechanisms by which they influence the controlled and autonomous regulation of behavior.
}

requirements for the effective cognitive functioning of geographically dispersed teams. As demonstrated by Cramton (2001), an inability to maintain "mutual knowledge" can compromise the effectiveness of these teams, thus placing a premium on human factors work directed toward the refinement of computermediated communication systems. These systems and related technologies have the potential to support the development of transactive memory and the various forms of team mental models reviewed above. Unfortunately, however, theory (Griffith \& Neale 2001, Griffith et al. 2003) and empirical evidence (Baltes et al. 2002, Gibson \& Gibbs 2006, Malhotra et al. 2001) concerning the effectiveness of these systems is somewhat mixed, thus implying a need to probe further, across a diversity of contexts, into the social psychological and technological dynamics that promote and inhibit the attainment of mutual knowledge in virtual teams.

Several empirical studies within the current review period have investigated the cognitive effects of job design. A field study reported by Leach et al. (2003), for example, demonstrated that an empowerment initiative significantly increased shop floor operatives' job knowledge, particularly among lessexperienced employees. The initiative also significantly increased workers' self-efficacy and concomitantly decreased felt job strain. In related work, Elsbach \& Hargadon (2006) examined ways of increasing organizational creativity by designing workdays to comprise an appropriate mix of cognitively challenging and "mindless" work.

Meanwhile, empirical work on operators' mental models of process control tasks and associated technological systems, both at the individual (e.g., Jones \& Endsley 2000) and team (e.g., Sauer et al. 2006, Waller et al. 2004) levels of analysis, has also continued. The related construct of situation awareness also continues to enjoy widespread conceptual and empirical attention. Defined as knowledge of a more dynamic and fleeting form, as distinct from that which is more stable and long-term 
in nature, situation awareness has been postulated as a determinant of the successful operation of complex human-machine systems, both at the individual (Sohn \& Doane 2004) and team (Gorman et al. 2006) levels of analysis. Research continues concerning the development and validation of psychometric tests for detecting the cognitive skills and abilities underpinning situation awareness (e.g., Sohn \& Doane 2004), and the design of humanmachine interfaces (e.g., Remington et al. 2000) and team processes (e.g., Roth et al. 2006), with a view to enhancing situation awareness. A further consideration concerns the allocation of function (i.e., individual versus team versus technology) to optimize system performance through the attainment and maintenance of situation awareness (see, e.g., Parasuraman 2000).

Recognizing that work design theory has not coevolved in line with modern work practices and organizational forms, there have been several recent attempted reconceptions to incorporate cognitive and emotional factors (Clegg \& Spencer 2007, Daniels 2006, Parker et al. 2001). For example, Parker et al. (2001) have proposed an "elaborated model of work design," in which the traditional work characteristics of extant job and work design theories (e.g., skill variety, autonomy, feedback; Hackman \& Oldham 1976) are augmented by the inclusion of cognitive demands (e.g., attentional and problem-solving demands). Within their model, cognitive outcomes relating to the use, creation, and transfer of knowledge can be facilitated or inhibited by work design factors. In a related methodological advance, Morgeson \& Humphrey (2006) have reported the development and validation of a new work design questionnaire incorporating scales to assess cognitive demands (i.e., information processing and problem solving). ${ }^{5}$ However, when this and the related recent reconceptions of work design are

\footnotetext{
${ }^{5}$ In a further methodological advance, Wallace \& Chen (2005) have developed and validated a measure of cognitive failure. This instrument is potentially promising in a
}

considered in the light of the cognitive design challenges arising in the context of new work practices and organizational forms, some of which we have enumerated above, it is clear that there are many gaps in the current knowledge base that need addressing before designers of the contemporary workplace can derive psychologically sound solutions to meet these challenges.

\section{Leadership}

Lord \& Emrich's (2000) review traced the origins and development of "the cognitive revolution in leadership research," covering major advances up to the commencement of the current review period. They identified two major streams of work, the first centering on individual and dyadic cognition, the second on collective cognition. A number of major advances have occurred in each stream within the current period.

Within the individual and dyadic stream, social information processing theories such as leadership categorization theory (e.g., Lord et al. 1984) and implicit leadership theory (e.g., Lord \& Maher 1991) continue to inspire research on followers' perceptions and evaluations of leaders (e.g., Epitropaki \& Martin 2005). More generally, work continues to explore the traits (e.g., intelligence; Judge et al. 2004a) and information processing capabilities and associated knowledge structures (i.e., expertise; Lord \& Hall 2005) that underpin the emergence and development of leaders. The rich vein of work analyzing leadermember relations and trust in leaders has also taken a decidedly cognitive turn. For example, researchers have begun to explore followers' attributions of leader characteristics and associated behaviors and outcomes, including the attribution of charismatic influence attempts (e.g., Cha \& Edmondson 2006, Dasborough \& Ashkanasy 2002) and the attributional basis

variety of applications, not least for measuring the cognitive outcomes of work design interventions. 
BDT: behavioral decision theory of trust in leadership (e.g., Dirks 2000), including an examination of cross-cultural variations (Ensari \& Murphy 2003).

Researchers have also investigated the nature and extent of variations in leadership prototypes across organizational (Dickson et al. 2006) and national (Brodbeck et al. 2000) cultures. These studies evidence a tension regarding the extent to which leadership prototypes and related mental representations should be viewed as relatively stable and enduring or as dynamic and fleeting. In a significant theoretical advance, Lord et al. (2001) developed a cognitive model of the way in which individuals mentally represent key leadership concepts (e.g., prototypes, schemas, implicit leadership theories) that allows for both the stability of leadership concepts and their changeability over time and across contexts, based on connectionist approaches to the modeling of cognitive architecture.

Arguably, the most significant developments during the current review period within the collective cognition research stream concern advances in understanding organizational sensemaking. A number of new concepts have been proposed to account more fully for the nature of leaders' attempts to influence and transform the attitudes and beliefs of their followers. For example, in an ethnographic study of a network marketing organization, Pratt (2000) demonstrated how successful leaders adopt "sense-breaking" tactics in an attempt to stimulate "seekership" among followers (i.e., the search for new meaning) with a view to increasing their identification with the organization. More generally, researchers are increasingly recognizing the importance of augmenting the analysis of such hierarchically driven, top-down sensemaking and sense-giving leadership processes with the study of the bottom-up influence processes adopted variously by a range of lower-level stakeholders, including middle managers, in the management of meaning (e.g., Balogun \& Johnson 2004, Maitlis 2005).

The recent introduction of the social identity approach into the leadership domain holds considerable potential as a conceptual bridge across the individual/dyadic and collective cognition streams. Hogg's (2001) formulation, which brings together the voluminous literatures on prototypicality, social attraction, and attribution and information processing, provides a basis for understanding leadership processes in situations where group membership is particularly salient. Building on this approach, there has been an increasing volume of work demonstrating that individuals are recognized and evaluated as emergent leaders in accordance with their degree of fit with the prototype of the salient ingroup (e.g., Pierro et al. 2005, van Knippenberg \& van Knippenberg 2005), as opposed to their fit with more generic leadership schemas or categories (cf. Lord et al. 1984). In two related developments, social identity theory has been applied to the analysis of leader-member exchange relationships (Hogg et al. 2005) and transformational leadership processes (Kark et al. 2003). For a more extensive review of social identity applications in leadership theory and research, see van Knippenberg et al. (2004).

\section{Organizational Decision Making}

In a previous section, we drew attention to the distinction between the computational and interpretive perspectives on cognition in organizations. Behavioral decision theory (BDT) - the epitome of the computational perspective-has historically dominated, and continues to dominate, much of the literature pertaining to the cognitive analysis of organizational decisions (for reviews, see Highhouse 2001, Neale et al. 2006). However, over recent years the adequacy of this approach has been called into question on philosophical, theoretical, and methodological grounds.

First, Gigerenzer and colleagues (e.g., Gigerenzer 1991, Gigerenzer \& Goldstein 1996) maintain that many of the basic laboratory tasks employed in BDT experiments lack ecological validity (cf. Kahneman \& Tversky 1996). Predicated upon a fundamentally 
different conception of Simon's bounded rationality notion from that construed by traditional BDT researchers, known as ecological rationality, they have identified a new class of heuristics, "fast and frugal," that they maintain are adaptively matched to the informational structure and demands of decision makers' environments. Within the current review period, there have been several extensions and applications of this research to organizationally relevant decisions. However, in the main this work has been conducted within the confines of the laboratory (e.g., Bryant 2007, Newell et al. 2003) or employed simulated data to test competitively the performance of fast and frugal heuristics against their conventional counterparts (e.g., Hogarth \& Karelaia 2005), thus casting doubt on its generalizability to real-world contexts. Moreover, only a limited number of studies have investigated simple decision heuristics used by human participants in natural settings (e.g., Astebro \& Elhedhli 2006). Overall, these studies have yielded mixed findings regarding the extent to which decision makers actually rely on fast and/or frugal heuristics and with what effect. Clearly, therefore, there is a need for further validation of this approach in both controlled and organizational field settings.

Second, researchers grouped under the umbrella of naturalistic decision making (NDM) reject the notion of equivalency between the sparse confines of the laboratory and the infinitely richer settings in which organizational decision makers conduct their everyday affairs, thus implying the need for NDM researchers to evolve their own context-specific concepts, theories, and methods. The origins of NDM lie in studies of domain experts making complex, high stakes, and ill-structured decisions under time pressure, often in dangerous situations (Lipshitz et al. 2001). In theoretical terms, Klein's (1993) recognition-primed decision making model, with its emphasis on the crucial role of pattern recognition in obviating the need for extensive deliberation of multiple alternatives, epitomizes the NDM approach. Within the current review period, work on NDM has gathered momentum, both in organizational (Lipshitz et al. 2006) and human factors (e.g., Lipshitz \& Cohen 2005, Perrin et al. 2001, Wiggins \& Bollwerk 2006) applications. By way of illustration, Roth et al. (2006) employed cognitive task analysis to study the decision processes of dispersed employees in railroad operations, highlighting the potential of communication technologies for facilitating situation awareness. Several work design challenges identified in this study resonate with the problems outlined above concerning the attainment and maintenance of mutual knowledge and shared cognition in dispersed and collocated groups. ${ }^{6}$

The above developments notwithstanding, as noted above, conventional BDT research continues to play a central role in the analysis of organizationally relevant decisions. Within the current review period, there have been numerous applications and extensions of this work, ranging from the continued analysis of framing effects (Hodgkinson et al. 2002, Kuvaas \& Selart 2004, Wright \& Goodwin 2002), escalation behavior (Bragger et al. 2003), and confirmation bias (Russo et al. 2000), to the application of Janis \& Mann's classic conflict theory of decision making (Hodgkinson \& Wright 2002).

\section{Organizational Change and Development}

Organizational change and development was last reviewed in this series by Weick \& Quinn (1999). During the interim period, there have been many advances. Accordingly, we review selectively developments centered on the cognitive analysis of the strategic management of organizations (for a more extensive survey of these developments, see Hodgkinson \&

\footnotetext{
${ }^{6} \mathrm{~A}$ third challenge to the conventional BDT orthodoxy comes from Sutcliffe \& Weick's (2008) provocative essay in which they reconceptualize information overload in organizational decision making as a problem of interpretation rather than computation. However, it remains to be seen how far this perspective will inform new empirical work that goes beyond the insights of NDM research.
}

NDM: naturalistic decision making 
Sparrow 2002). The rationale for focusing on this work is its potential importance as a vehicle for leveraging up the strategic influence of the I/O psychology profession as a whole. For present purposes, it is analytically convenient to consider strategic management as encompassing three major sets of issues: analysis, choice, and implementation. In so doing, we do not seek to imply a linear or lockstep process. In practice, organizational strategies are as much the product of unplanned emergence as rational analysis, and a myriad of multilevel influences mediate and/or moderate the links between formal attempts to influence the strategic direction of the organization (i.e., its intended strategy) and its realized strategy (Mintzberg \& Waters 1985).

Strategic analysis involves understanding the strategic position of the organization, its environment, resources, values, and objectives. Changes in cognitive representations can aid organizational adaptation by shifting attention, yet ingrained schemata can constitute barriers to organizational and industrial change (Bogner \& Barr 2000). Accordingly, within the current review period, work has continued on the analysis of managers' mental representations of the structure and dynamics of competition in industries and markets, with a view to identifying patterns of belief convergence and divergence within and across organizations (e.g., Daniels et al. 2002, Hodgkinson 2005, Johnson \& Hoopes 2003, McNamara et al. 2002, Osborne et al. 2001). The primary aim of this stream of work is to illuminate the socio-cognitive processes underpinning the development of competitive positioning strategies and associated adaptive mechanisms that afford collective protection to, and drive the performance advantages of, particular groups of competing firms, but also serve as potential sources of inertia and myopia. Recent studies have incorporated a range of methodological step changes, including prospective longitudinal research designs, mathematical simulation techniques, and the use of advanced multivariate analysis techniques, thereby overcoming the weaknesses of the small scale, cross-sectional investigations that typified much of the earlier work in this stream. Complementing this stream of work centered on the external environment of the organization, there has been a growing interest in the cognitive microfoundations of the internal capabilities that promote sustainable competitive advantage, organizational learning and adaptation (e.g., Berson et al. 2006, Gavetti 2005, Lane et al. 2006).

Strategic choice involves the formulation, evaluation, and selection of possible courses of action. As discussed in the previous section, within the current review period researchers have applied and extended a range of BDT concepts and theories, with a view to explaining departures from rationality in strategic choice and related processes and the development of interventions to alleviate such effects. Although we have no wish to see this body of work discontinued, the fast and frugal and NDM approaches also surveyed above have much to offer in this domain of application, especially in the analysis of strategic choice processes in the high-velocity, uncertain business environments that characterize the operating conditions of many contemporary organizations (Brown \& Eisenhardt 1997).

From a cognitive standpoint, arguably the most pressing research issue with regard to strategy implementation (the translation of strategy into action) is to develop insights into the processes and mechanisms that facilitate, or more frequently inhibit, attempts to equip employees to adapt to organizational change initiatives in ways that yield positive individual and collective outcomes, including personal well being and organizational citizenship behavior. Rousseau (2001) has advanced a schema theory of psychological contract formation and change that might account for employee resistance to such initiatives. Rousseau maintains that psychological contracts are encoded in mental models (i.e., schemas) that are relatively malleable during the early stages of the employment relationship. However, once established, like the mental models of competitive positioning strategies held by 
organizational decision makers, employees' mental models of the psychological contract become resistant to change, leading to inertia and inflexibility. Although Rousseau's theory closely accords with several other formulations concerning employee resistance to organizational change programs, including total quality (Reger et al. 1994) and empowerment (Labianca et al. 2000) initiatives, it has yet to be validated empirically. In addition to these schema-based theories, recently both attribution theory (Martinko et al. 2002, Repenning \& Sterman 2002) and social identity theory (e.g., Fiol 2002, Haslam et al. 2003) have been posited as lenses through which to study the socio-cognitive mechanisms that might promote or inhibit adaptation to organizational change initiatives and the factors that give rise to counterproductive workplace behaviors.

\section{Individual Differences}

Many cognitively oriented studies within the nine domains surveyed above have routinely incorporated assessments of individual differences, including attributional style (Silvester et al. 2003), locus of control ( $\mathrm{Ng}$ et al. 2006), and need for closure (Ellis \& Davidi 2005, Pierro et al. 2005). However, two groups of variables are especially prominent in the overall body of work surveyed, namely, selfefficacy and related constructs (e.g., core-self evaluation) and cognitive style and associated constructs pertaining to the processing of information (e.g., decision style, cognitive strategy). ${ }^{7}$

Self-efficacy continues to be seen as a pervasive driver and outcome of cognitive functioning in organizations, influencing positively learning (Chen et al. 2000), cognitive, affective-motivational and behavioral training outcomes (Colquitt et al. 2000), and

\footnotetext{
${ }^{7}$ In addition, numerous studies continue to demonstrate the power of general mental ability and specific cognitive abilities as predictors of work-related performance. However, a detailed consideration of this work would warrant a stand-alone review (for representative findings, see Salgado et al. 2003).
}

responses to organizational change (Wanberg \& Banas 2000). Despite this popularity, equivocality persists regarding the most appropriate way of conceptualizing task- and contextspecific self-efficacy in relation to its putative antecedents and consequences and the higherorder generalized self-efficacy construct (e.g., Chen et al. 2000, Yeo \& Neal 2006). In recent years, there has been marked interest in the emergence and effects of collective efficacy in organizational teams and groups (for a review, see Ilgen et al. 2005; see also Srivastava et al. 2006, Tasa et al. 2007). More generally, two challenges have recently been mounted to the primacy of self-efficacy. First, several replications and extensions of earlier findings have shown that high self-efficacy can impair performance by reducing effort once goals are within reach (Vancouver 2005, Vancouver et al. 2002, Yeo \& Neal 2006), although these findings have been questioned on methodological grounds (Bandura \& Locke 2003). Second, although meta-analytic findings from the beginning of the current review period support the idea that self-efficacy plays an important role in determining work-related performance (Judge \& Bono 2001), a more recent meta-analysis conducted by Judge et al. (2007) showed that this effect is significantly reduced when controlling for more distal individual differences (e.g., mental ability, Big Five personality traits, and experience).

There have been recent attempts in several domains to group multiple specific traits pertaining to self-concept (e.g., self-esteem, self-efficacy, locus of control, and emotional stability) into a higher-order construct termed "core self-evaluation" (for a review, see Judge et al. 2004b). Hiller \& Hambrick (2005), for example, have applied this construct to analyze the behavior of company executives, while Stajkovic (2006) has developed the related construct of core confidence. More generally, this approach reveals a wider tension in organizational research regarding the extent to which, and under what conditions, higher-order traits or more focused narrow-band traits are more appropriate 
for capturing within- and between-individual variations in cognition and for predicting various work-related outcomes. Potentially, a myriad of individual differences could moderate or mediate the cognitive functioning of individuals and teams in organizational settings. One potentially fruitful approach to systematize the search for such links would be to map relevant narrow-band constructs onto higher-level organizing frameworks, such as the Five Factor Model, with a view to identifying the information processing characteristics and consequences of alternative configurations of personality.

Individual differences in information processing tendencies encompass a range of cognitively based variables that have been adopted widely in the analysis of organizational behavior, reflecting in general terms the distinction between analytic and intuitive processing (Chaiken \& Trope 1999). For example, cognitive style has been shown to influence decision-making performance (Levin et al. 2000, Parker \& Fischhoff 2005), perceptions of cognitive biases (Tetlock 2000), and the nature and quality of leader-member exchange (Allinson et al. 2001). However, debates have continued within the current review period regarding the psychometric status of measures of cognitive style, and views are now polarized. One view maintains that analysis and intuition are served by a common underlying cognitive system, that individuals have a stable overarching preference for one approach or the other, and that these tendencies are organized along a unidimensional, bipolar continuum (see, e.g., Allinson et al. 2001, Hayes et al. 2003). In contrast, a second perspective accords greater agency to individuals, arguing that analytic and intuitive processing capabilities are served by independent cognitive systems that permit individuals to switch back and forth from one approach to the other as required, albeit moderated to some extent by stylistic preferences (see, e.g., Dane \& Pratt 2007; Hodgkinson et al. 2008; Hodgkinson \& Sadler-Smith 2003a,b). These debates have important implications for future work, following recent calls to examine the role individual differences in information processing might play in shaping cognitive functioning in various organizational domains, including the adoption of fast and frugal decision heuristics (e.g., Newell et al. 2003) and the selection, development, and leadership of strategy-making teams (Hodgkinson \& Clarke 2007).

\section{METHODOLOGICAL DEVELOPMENTS}

Many important advances have occurred within the current review period in respect of cognitive task analysis methods and related cognitive mapping techniques for eliciting and representing individual (e.g., Fowlkes et al. 2000, Patrick \& James 2004) and collective (e.g., Arthur et al. 2005) knowledge (for detailed overviews, see Cooke et al. 2000, Hodgkinson \& Sparrow 2002, Langan-Fox et al. 2000, Schraagen et al. 2000). Four issues in respect of these methods continue to warrant scholarly attention.

The first issue concerns the question of what methods are best suited to what types of application. Researchers have established an impressive array of procedures for eliciting procedural and declarative knowledge, but the psychometric adequacy of many of these techniques across their various domains of application has yet to be determined.

The second issue concerns the relative merits of idiographic versus nomothetic approaches to knowledge elicitation. This debate has arisen in connection with repertory grid (Daniels \& Johnson 2002; Hodgkinson 2002, 2005; Wright 2004) and causal cognitive mapping (Narayanan \& Armstrong 2005) techniques. In recent years several hybrid approaches have been devised that combine the strengths of idiographic and nomothetic procedures. The main advantage of these approaches is that they yield data of a form amenable to systematic comparison, a vital prerequisite for developing cumulative insights across contexts and time periods, 
while ensuring that the elicitation task is meaningful to participants. In this connection, Clarkson \& Hodgkinson (2005) have reported the development of new software to support hybrid approaches to causal cognitive mapping for use with large samples, while Hodgkinson (2005) has devised a hybrid approach to repertory grid elicitation and analysis for similar large-scale use.

The third issue concerns the nature of the cognitive processes triggered by the act of elicitation. For instance, different approaches to causal cognitive mapping have been shown to yield cause maps with significantly different structural characteristics (Hodgkinson et al. 2004), thus raising the question as to whether the products of various elicitation techniques should be viewed as mere artifacts of the production process or as isomorphic with the underlying cognitive processes and mental representations of substantive concern. The importance of this issue has been heightened following recent progress in cognitive science regarding the conceptualization of causal mental models and related constructs (Sloman \& Hagmayer 2006), placing causal cognitive mapping techniques on firmer theoretical foundations.

Fourth, the vast majority of extant methods are designed to elicit conceptual knowledge of a form accessible through verbal report or other forms of conscious awareness. Although researchers have long recognized the importance of the less conscious aspects of cognition in organizational life (e.g., implicit knowledge, intuition), until recently there has been little advancement in methods for assessing these forms of knowledge in applied field settings. There are, however, encouraging signs of progress. Bing et al. (2007), for example, outline methods for assessing integratively the implicit and explicit knowledge underpinning personality prototypes. Developments in the assessment of implicit attitudes (e.g., Fazio \& Olson 2003, Haines \& Sumner 2006) and at the forefront of social cognitive neuroscience (Lieberman 2007) also hold considerable promise for exploring the various nonconscious processes that researchers are beginning to study in organizational contexts, including implicit affective processes (Kelly \& Barsade 2001), subconscious motivation (Stajkovic et al. 2006), and nonconscious priming (Kay et al. 2004).

\section{FUTURE CHALLENGES}

Clearly, the period encompassed by this review has been most eventful. Looking ahead, researchers of cognition in organizations need to confront five major tensions if the field is to advance further.

\section{Crossing the Traditions}

We began this review with the observation that the complexities of the modern workplace are such that there is a need for increased cooperation across the organizational and human factors traditions. As we have seen, nowhere is this need more apparent than in the domain of work design and $\operatorname{cog}$ nitive ergonomics. On the human factors side, concepts such as situation awareness and team mental models have provided useful insights into the cognitive functioning of complex human-machine systems and the system requirements for the attainment of shared cognition. On the organizational side, however, although work design theorists and researchers have called for the refinement of concepts and models to meet the design challenges implied by such systems, we are still a long way from a truly integrated approach capable of meeting these cognitive requirements while also ensuring that the positive benefits associated with interventions based on conventional job and work design principles are not lost in the process.

The work of Zhang and colleagues (e.g., Rinkus et al. 2005, Zhang et al. 2002) on the design of complex distributed information systems and the work of Agarwal \& Karahanna (2000) on the intrinsic motivational properties of information technology provide convenient illustrations of the limitations of 
existing efforts to bring the two traditions together within a unified approach. Zhang and colleagues have drawn upon the distributed cognition, human-computer interaction, organizational learning, and organizational memory literatures in an attempt to derive a comprehensive framework for meeting the design challenges of distributed information systems, but they have failed to incorporate any of the insights of classic or contemporary theory and research on job and work design (e.g., Hackman \& Oldham 1976, Parker et al. 2001). Agarwal \& Karahanna (2000) have similarly drawn upon a diversity of literatures (e.g., work on the trait of absorption, the state of flow and cognitive engagement) to derive their notion of cognitive absorption, a multidimensional construct reflecting the extent to which individuals are immersed in information technology, yet neglected to consider the voluminous body of theory and research on work motivation. These oversights are understandable given the independent histories of the two traditions, but the time has surely come to develop appropriate bridging mechanisms to yield the required progress.

\section{Crossing the Domains}

Throughout our review, we have observed repeatedly that the five dominant theoretical perspectives identified at the outset pervade research across the 10 domains surveyed, albeit to varying extents. Schema theory and related notions of mental representations, for example, have emerged in a variety of guises as a basic mechanism for explaining cognitive bias and inertia at the individual, group, organizational, and interorganizational levels of analysis, from work groups and teams to leadership and organizational change and development. Social identity theory and related conceptions, attribution theory, and sensemaking notions have been no less ubiquitous.

Given this commonality, it is tempting to call for future research to focus on the development of theoretical accounts that cut across the various domains. Indeed, several notewor- thy attempts have been made to develop such accounts. For instance, researchers have portrayed the social identity approach, combining self/social categorization and social identity theories, as an overarching conception capable of providing unified insights across multiple domains (see, e.g., Haslam 2001, Haslam et al. 2003, Hogg \& Terry 2000). In general, however, it would be unwise to strive uniformly for broad theoretical accounts of cognitive mechanisms and processes that cut across domains to the exclusion of detailed theoretical specifications that offer intricate descriptions of domain-specific phenomena.

\section{Integrative Understanding Within Domains}

A third tension concerns the extent to which integrating the various theories that dominate particular domains might yield greater insights than if they continue to advance as independent formulations. As we saw in the domains of personnel selection and assessment (e.g., Ployhart \& Harold 2004) and work motivation (e.g., DeShon \& Gillespie 2005, Latham \& Pinder 2005), there have been a number of such calls and attempts, with a view to developing more complete accounts of the focal phenomena. Over the longer term, however, it might prove more valuable for the advancement of science and practice within and between each domain to pit alternative formulations against one another, with a view to identifying the circumstances in which they provide greater or less understanding and predictive power. In the case of leadership, for example, future research could fruitfully investigate the relative contributions of social identity, attribution, and leader categorization formulations in the prediction and management of leader-member exchange relationships.

\section{The Challenge of Emotion}

In seeking to advance understanding of behavior in the workplace, a fourth tension 
concerns the extent to which it is possible and/or desirable to augment current cognitive conceptions by incorporating affective variables, as opposed to developing entirely new bodies of theory and research. Recent advances in social cognitive neuroscience (Phelps 2006) are providing vital signposts as to how the emerging work investigating the dynamic interplay between cognition and emotion in organizations might be elevated to a new level (cf. Brief \& Weiss 2002, Fisher \& Ashkanasy 2000). For example, the insights of this work could inform research that has begun to identify the mechanisms by which emotion impairs and aids learning (e.g., LePine 2004) and refine understanding of how emotional traits and states determine the extent to which organizational decision makers rely on controlled and automatic information processing (Daniels et al. 2004). Although it is acknowledged that both anticipated (e.g., fear, dread) and felt (e.g., anxiety, stress) emotions can constrain behavior relating to difficult decisions, current understanding of these mechanisms and their effects in organizational settings is limited (cf. Maitlis \& Ozcelik 2004, Wong et al. 2006). In conceptual terms, researchers need to move beyond linear, single-step analyses of affective influences on cognition or conversely of the cognitive determinants of affect (cf. Brief \& Weiss 2002). Suitably dynamic conceptions would encapsulate the recursive processes by which affectively informed appraisals produce discrete emotions, in turn shaping subsequent cognitions, both within discrete episodes and over time (for current progress in this regard, see Beal et al. 2005).

\section{Laboratory Versus Field}

The fifth tension constitutes a methodological challenge. Many of the articles across the substantive domains we have surveyed report studies of cognition in the laboratory rather than cognition in organizations, as such. However, the relative predominance of labo- ratory versus field studies varies considerably between domains. For example, research into cognition in work groups and teams continues to be heavily reliant on laboratory studies. In cases where the primary objective is merely to validate further well-established principles and concepts, researchers might usefully supplant such laboratory methods with methods of the sort pioneered by Hutchins (1995) and NDM researchers for studying cognition in situ (cf. Waller et al. 2004). However, in those cases where new concepts have begun to emerge (e.g., MTSs), a judicious combination of laboratory and field methods seems entirely appropriate. A blanket call for more field and fewer laboratory studies is, therefore, unwarranted. In the final analysis, researchers must select the mix of methods most appropriate to the research question(s) under investigation, taking into account the overall maturity of the theories and concepts underpinning their work.

\section{CONCLUSIONS}

Research on cognition in organizations is thriving. We have arrived at two general conclusions from the foregoing survey. First, reflecting the fact that this body of work now constitutes a multidisciplinary endeavor, there are clear signs of growing collaboration between researchers across the organizational and human factors traditions, but given the scale and complexity of the challenges confronting the modern workplace, we need even greater cooperation. Arguably, in going forward the greatest challenge is one of measurement-how best to capture, represent, and interpret conscious and nonconscious forms of cognition within and between organizations, as unobtrusively as possible in a time-sensitive manner. Second, although a number of common theoretical perspectives pervade each of the 10 substantive domains reviewed, it would be most unfortunate if the field were to degenerate into a series of internecine struggles for cross-domain theoretical supremacy. On the contrary, the plurality 
of perspectives augers well for the long-term health and vibrancy of research on managerial and organizational cognition and the $\mathrm{I} / \mathrm{O}$ psychology field in general. As cognitive theo- ries, concepts, and methods enter a new phase of maturity, we foresee a host of new insights emerging across the entire spectrum of organizational life.

\section{ACKNOWLEDGMENTS}

We thank Prithviraj Chattopadhyay, Chris Clegg, Susan T. Fiske, Kevin Ford, Alex Haslam, Peter Herriot, Denise Rousseau, Eduardo Salas, Mary Waller, and Karl Weick for their helpful and constructive comments on an earlier draft. We also gratefully acknowledge the financial support of the UK ESRC/EPSRC Advanced Institute of Management Research in the preparation of this article (under grant number RES-331-25-0028).

\section{LITERATURE CITED}

Agarwal R, Karahanna E. 2000. Time flies when you're having fun: cognitive absorption and beliefs about information technology usage. MIS Q. 24:665-94

Allinson CW, Armstrong SJ, Hayes J. 2001. The effects of cognitive style on leader-member exchange: a study of manager-subordinate dyads. F. Occup. Organ. Psychol. 74:201-20

Arnold P, Farrell MJ. 2002. Can virtual reality be used to measure and train surgical skills? Ergonomics 45:362-79

Arthur W, Edwards BD, Bell ST, Villado AJ, Bennett W. 2005. Team task analysis: identifying tasks and jobs that are team based. Hum. Factors 47:654-69

Ashforth BE, Mael F. 1989. Social identity theory and the organization. Acad. Manage. Rev. $14: 20-39$

Astebro T, Elhedhli S. 2006. The effectiveness of simple decision heuristics: forecasting commercial success for early-stage ventures. Manage. Sci. 52:395-409

Austin JR. 2003. Transactive memory in organizational groups: the effects of content, consensus, specialization, and accuracy on group performance. 7. Appl. Psychol. 88:866-78

Balogun J, Johnson G. 2004. Organizational restructuring and middle manager sensemaking. Acad. Manage. 7. 47:523-49

Baltes BB, Dickson MW, Sherman MP, Bauer CC, LaGanke JS. 2002. Computer-mediated communication and group decision making: a meta-analysis. Organ. Behav. Hum. Decis. Process. 87:156-79

Bandura A. 1977. Self-efficacy: toward a unifying theory of behavioral change. Psychol. Rev. $84: 191-215$

Bandura A, Locke EA. 2003. Negative self-efficacy and goal effects revisited. F. Appl. Psychol. 88:87-99

Bartlett FC. 1932. Remembering: A Study in Experimental and Social Psychology. Cambridge, UK: Cambridge Univ. Press

Beal DJ, Weiss HM, Barros E, MacDermid SM. 2005. An episodic process model of affective influences on performance. F. Appl. Psychol. 90:1054-68

Bell BS, Kozlowski SWJ. 2002. Adaptive guidance: enhancing self-regulation, knowledge, and performance in technology-based training. Pers. Psychol. 55:267-306

Bell BS, Wiechmann D, Ryan AM. 2006. Consequences of organizational justice expectations in a selection system. F. Appl. Psychol. 91:455-66

Berson Y, Nemanich LA, Waldman DA, Galvin BM, Keller RT. 2006. Leadership and organizational learning: a multiple levels perspective. Leadersh. Q. 17:577-94 
Bing MN, LeBreton JM, Davison HK, Migetz DZ, James LR. 2007. Integrating implicit and explicit social cognitions for enhanced personality assessment: a general framework for choosing measurement and statistical methods. Organ. Res. Methods 10:13679

Bogner WC, Barr PS. 2000. Making sense in hypercompetitive environments: a cognitive explanation for the persistence of high velocity competition. Organ. Sci. 11:212-26

Bragger JD, Hantula DA, Bragger D, Kirnan J, Kutcher E. 2003. When success breeds failure: history, hysteresis, and delayed exit decisions. F. Appl. Psychol. 88:6-14

Brandon DP, Hollingshead AB. 2004. Transactive memory systems in organizations: matching tasks, expertise, and people. Organ. Sci. 15:633-44

Brief AP, Weiss HM. 2002. Organizational behavior: affect in the workplace. Annu. Rev. Psychol. 53:279-307

Broadbent DE. 1958. Perception and Communication. London: Pergamon

Brodbeck FC, Frese M, Akerblom S, Audia G, Bakacsi G, et al. 2000. Cultural variation of leadership prototypes across 22 European countries. F. Occup. Organ. Psychol. 73:1-29

Brown KG. 2001. Using computers to deliver training: Which employees learn and why? Pers. Psychol. 54:271-96

Brown SL, Eisenhardt KM. 1997. The art of continuous change: linking complexity theory and time-paced evolution in relentlessly shifting organizations. Admin. Sci. Q. 42:1-34

Bryant DJ. 2007. Classifying simulated air threats with fast and frugal heuristics. F. Behav. Decis. Mak. 20:37-64

Bunderson JS. 2003. Recognizing and utilizing expertise in work groups: a status characteristics perspective. Admin. Sci. Q. 48:557-91

Burke CS, Stagl KC, Salas E, Pierce L, Kendall D. 2006. Understanding team adaptation: a conceptual analysis and model. F. Appl. Psychol. 91:1189-207

Cannon-Bowers JA, Salas E. 2001. Reflections on shared cognition. F. Organ. Behav. 22:195202

Card S, Moran TP, Newel A. 1983. The Psychology of Human-Computer Interaction. Hillsdale, NJ: Erlbaum

Carpenter MA. 2002. The implications of strategy and social context for the relationship between top management team heterogeneity and firm performance. Strateg. Manage. 7 . 23:275-84

Cha SE, Edmondson AC. 2006. When values backfire: leadership, attribution, and disenchantment in a values-driven organization. Leadersh. Q. 17:57-78

Chaiken S, Trope Y, eds. 1999. Dual Process Theories in Social Psychology. New York: Guildford

Chattopadhyay P, Glick WH, Miller CC, Huber GP. 1999. Determinants of executive beliefs: comparing functional conditioning and social influence. Strateg. Manage. 7. 20:763-89

Chen G, Gully SM, Whiteman JA, Kilcullen RN. 2000. Examination of relationships among trait-like individual differences, state-like individual differences, and learning performance. F. Appl. Psychol. 85:835-47

Clarkson GP, Hodgkinson GP. 2005. Introducing Cognizer ${ }^{\mathrm{TM}}$ : a comprehensive computer package for the elicitation and analysis of cause maps. Organ. Res. Methods 8:317-41

Clegg CW, Spencer C. 2007. A circular and dynamic model of the process of job design. $\mathcal{F}$. Occup. Organ. Psychol. 80:321-39

Cleveland JN, Murphy KR. 1992. Analyzing performance appraisal as a goal directed behavior. Res. Pers. Hum. Resour. Manage. 10:121-85

Colquitt JA, LePine JA, Noe RA. 2000. Toward an integrative theory of training motivation: a meta-analytic path analysis of 20 years of research. F. Appl. Psychol. 85:678-707
A field study exploring how group members attribute expertise using task and social category cues to develop transactive memory. 
Cooke NJ, Salas E, Cannon-Bowers JA, Stout RJ. 2000. Measuring team knowledge. Hum. Factors 42:151-73

Craik K. 1943. The Nature of Explanation. Cambridge, UK: Cambridge Univ. Press

Cramton CD. 2001. The mutual knowledge problem and its consequences for dispersed collaboration. Organ. Sci. 12:346-71

Dane E, Pratt MG. 2007. Exploring intuition and its role in managerial decision making. Acad. Manage. Rev. 32:33-54

Daniels K. 2006. Rethinking job characteristics in work stress research. Hum. Relat. 59:267-90

Daniels K, Harris C, Briner RB. 2004. Linking work conditions to unpleasant affect: cognition, categorization and goals. 7. Occup. Organ. Psychol. 77:343-63

Daniels K, Hartley R, Travers CJ. 2006. Beliefs about stressors alter stressors' impact: evidence from two experience-sampling studies. Hum. Relat. 59:1261-85

Daniels K, Johnson G. 2002. On trees and triviality traps: locating the debate on the contribution of cognitive mapping to organizational research. Org. Stud. 23:73-81

Daniels K, Johnson G, de Chernatony L. 2002. Task and institutional influences on managers' mental models of competition. Org. Stud. 23:31-62

Dasborough MT, Ashkanasy NM. 2002. Emotion and attribution of intentionality in leadermember relationships. Leadersh. Q. 13:615-34

DeChurch LA, Marks MA. 2006. Leadership in multiteam systems. F. Appl. Psychol. 91:311-29

DeShon RP, Gillespie JZ. 2005. A motivated action theory account of goal orientation. F. Appl. Psychol. 90:1096-127

Dewe P, Cooper CL. 2007. Coping research and the measurement of work related stress. In International Review of Industrial and Organizational Psychology, ed. GP Hodgkinson, JK Ford, pp. 141-91. Chichester, UK: Wiley

Dickson MW, Resick CJ, Hanges PJ. 2006. Systematic variation in organizationally-shared cognitive prototypes of effective leadership based on organizational form. Leadersh. Q. $17: 487-505$

Dirks KT. 2000. Trust in leadership and team performance: evidence from NCAA basketball. 7. Appl. Psychol. 85:1004-12

Edwards E, Lees FP, eds. 1974. The Human Operator in Process Control. London: Taylor \& Francis

Edwards JR. 1992. A cybernetic theory of stress, coping, and well-being in organizations. Acad. Manage. Rev. 17:238-74

Ellemers N, De Gilder D, Haslam SA. 2004. Motivating individuals and groups at work: a social identity perspective on leadership and group performance. Acad. Manage. Rev. 29:459-78

Ellis APJ. 2006. System breakdown: the role of mental models and transactive memory in the relationship between acute stress and team performance. Acad. Manage. 7. 49:576-89

Ellis S, Davidi I. 2005. After-event reviews: drawing lessons from successful and failed experience. 7. Appl. Psychol. 90:857-71

Elsbach KD, Hargadon AB. 2006. Enhancing creativity through "mindless" work: a framework of workday design. Organ. Sci. 17:470-83

Ensari N, Murphy SE. 2003. Cross-cultural variations in leadership perceptions and attribution of charisma to the leader. Organ. Behav. Hum. Decis. Process. 92:52-66

Epitropaki O, Martin R. 2005. From ideal to real: a longitudinal study of the role of implicit leadership theories on leader-member exchanges and employee outcomes. F. Appl. Psychol. 90:659-76

Faraj S, Sproull L. 2000. Coordinating expertise in software development teams. Manage. Sci. 46:1554-68 
Fazio RH, Olson MA. 2003. Implicit measures in social cognition research: their meaning and use. Annu. Rev. Psychol. 54:297-327

Ferguson E, Daniels K, Jones D. 2006. Negatively oriented personality and perceived negative job characteristics as predictors of future psychological and physical symptoms: a metaanalytic structural modeling approach. 7. Psychosom. Res. 60:45-52

Fiol CM. 2002. Capitalizing on paradox: the role of language in transforming organizational identities. Organ. Sci. 13:653-66

Fisher CD, Ashkanasy NM. 2000. The emerging role of emotions in work life: an introduction. 7. Organ. Behav. 21:123-29

Fletcher C. 2001. Performance appraisal and management: the developing research agenda. 7 . Occup. Organ. Psychol. 74:473-87

Ford JK, Kraiger K. 1995. The application of cognitive constructs to the instructional systems model of training: implications for needs assessment, design and transfer. In International Review of Industrial and Organizational Psychology, Volume 10, ed. CL Cooper, IT Robertson, pp. 1-48. Chichester, UK: Wiley

Fowlkes JE, Salas E, Baker DP, Cannon-Bowers JA, Stout RJ. 2000. The utility of event-based knowledge elicitation. Hum. Factors 42:24-35

Frese M, Zapf D. 1999. On the importance of the objective environment in stress and attribution theory. Counterpoint to Perrewe \& Zellars. F. Organ. Behav. 20:761-65

Gagne M, Deci EL. 2005. Self-determination theory and work motivation. F. Organ. Behav. 26:331-62

Gavetti G. 2005. Cognition and hierarchy: rethinking the microfoundations of capabilities development. Organ. Sci. 16:599-617

Gibson CB, Gibbs JL. 2006. Unpacking the concept of virtuality: the effects of geographic dispersion, electronic dependence, dynamic structure, and national diversity on team innovation. Admin. Sci. Q. 51:451-95

Gigerenzer G. 1991. How to make cognitive illusions disappear. Beyond heuristics and biases. In European Review of Social Psychology, ed. W Stroebe, M Hewstone, Vol 2, pp. 83-115. Chichester, UK: Wiley

Gigerenzer G, Goldstein DG. 1996. Reasoning the fast and frugal way: models of bounded rationality. Psychol. Rev. 103:650-69

Gilovich T, Griffith D, Kahneman D, eds. 2002. Heuristics and Biases: The Psychology of Intuitive fudgment. Cambridge, UK: Cambridge Univ. Press

Goldberg CB. 2005. Relational demography and similarity-attraction in interview assessments and subsequent offer decisions: Are we missing something? Group Organ. Manage. 30:597624

Gorman JC, Cooke NJ, Winner JL. 2006. Measuring team situation awareness in decentralized command and control environments. Ergonomics 49:1312-25

Griffith TL, Neale MA. 2001. Information processing in traditional, hybrid, and virtual teams: from nascent knowledge to transactive memory. In Research in Organizational Behavior, Volume 23, pp. 379-421. Amsterdam: JAI Elsevier

Griffith TL, Sawyer JE, Neale MA. 2003. Virtualness and knowledge in teams: managing the love triangle of organizations, individuals, and information technology. MIS Q. 27:265-87

Hackman JR, Oldham GR. 1976. Motivation through design of work: test of a theory. Organ. Behav. Hum. Perform. 16:250-79

Haines EL, Sumner KE. 2006. Implicit measurement of attitudes, stereotypes, and selfconcepts in organizations: teaching old dogmas new tricks. Organ. Res. Methods 9:536-53

Hambrick DC, Mason PA. 1984. Upper echelons: the organization as a reflection of its top managers. Acad. Manage. Rev. 9:193-206 
Demonstrates how managers' beliefs regarding the malleability of personal attributes influence their ability to recognize employee performance variations.
Surveys theory, research, and methodological advances in the analysis of the strategic management process from a cognitive standpoint.
Haslam SA. 2001. Psychology in Organizations: The Social Identity Approach. London: Sage

Haslam SA, Eggins RA, Reynolds KJ. 2003. The ASPIRe model: Actualizing Social and Personal Identity Resources to enhance organizational outcomes. F. Occup. Organ. Psychol. 76:83-113

Haslam SA, Reicher S. 2006. Stressing the group: social identity and the unfolding dynamics of responses to stress. F. Appl. Psychol. 91:1037-52

Hausknecht JP, Day DV, Thomas SC. 2004. Applicant reactions to selection procedures: an updated model and meta-analysis. Pers. Psychol. 57:639-83

Hayes J, Allinson CW, Hudson RS, Keasey K. 2003. Further reflections on the nature of intuition-analysis and the construct validity of the Cognitive Style Index. F. Occup. Organ. Psychol. 76:269-78

Heider F. 1958. The Psychology of Interpersonal Relations. New York: Wiley

Hennessey HW, Bernardin HJ. 2003. The relationship between performance appraisal criterion specificity and statistical evidence of discrimination. Hum. Resour. Manage. 42:143-58

Herriot P. 1989. Selection as a social process. In Advances in Selection and Assessment, ed. M Smith, IT Robertson, pp. 171-87. New York: Wiley

Herriot P. 2004. Social identities and applicant reactions. Int. 7. Sel. Assess. 12:75-83

Herrmann P, Datta DK. 2006. CEO experiences: effects on the choice of FDI entry mode. 7 . Manage. Stud. 43:755-78

Heslin PA, Latham GP, VandeWalle D. 2005. The effect of implicit person theory on performance appraisals. F. Appl. Psychol. 90:842-56

Highhouse S. 2001. Judgment and decision-making research: relevance to industrial and organizational psychology. In Handbook of Industrial, Work and Organizational Psychology: Volume 2-Organizational Psychology, ed. N Anderson, DS Ones, HK Sinangil, C Viswesvaran, pp. 314-31. London: Sage

Hiller NJ, Hambrick DC. 2005. Conceptualizing executive hubris: the role of (hyper) core self-evaluations in strategic decision-making. Strat. Manage. 7. 26:297-319

Hodgkinson GP. 2002. Comparing managers' mental models of competition: why self-report measures of belief similarity won't do. Org. Stud. 23:63-72

Hodgkinson GP. 2005. Images of Competitive Space: A Study of Managerial and Organizational Strategic Cognition. Basingstoke, UK: Palgrave Macmillan

Hodgkinson GP, Clarke I. 2007. Exploring the cognitive significance of organizational strategizing: a dual-process framework and research agenda. Hum. Relat. 60:243-55

Hodgkinson GP, Langan-Fox J, Sadler-Smith E. 2008. Intuition: a fundamental bridging construct in the behavioural sciences. Br. F. Psychol. 99:1-27

Hodgkinson GP, Maule AJ, Bown NJ. 2004. Causal cognitive mapping in the organizational strategy field: a comparison of alternative elicitation procedures. Organ. Res. Methods 7:326

Hodgkinson GP, Maule AJ, Bown NJ, Pearman AD, Glaister KW. 2002. Further reflections on the elimination of framing bias in strategic decision making. Strat. Manage. 7. 23:1069-76

Hodgkinson GP, Sadler-Smith E. 2003a. Complex or unitary? A critique and empirical reassessment of the Allinson-Hayes Cognitive Style Index. F. Occup. Organ. Psychol. 76:243-68

Hodgkinson GP, Sadler-Smith E. 2003b. Reflections on reflections ... on the nature of intuition, analysis and the construct validity of the Cognitive Style Index. 7. Occup. Organ. Psychol. 76:279-81

Hodgkinson GP, Sparrow PR. 2002. The Competent Organization: A Psychological Analysis of the Strategic Management Process. Buckingham, UK: Open Univ. Press

Hodgkinson GP, Wright G. 2002. Confronting strategic inertia in a top management team: learning from failure. Organ. Stud. 23:949-77 
Hogarth RM, Karelaia N. 2005. Simple models for multiattribute choice with many alternatives: when it does and does not pay to face trade-offs with binary attributes. Manage. Sci. 51:1860-72

Hogg MA. 2001. A social identity theory of leadership. Pers. Soc. Psychol. Rev. 5:184-200

Hogg MA, Martin R, Epitropaki O, Mankad A, Svensson A, Weeden K. 2005. Effective leadership in salient groups: revisiting leader-member exchange theory from the perspective of the social identity theory of leadership. Pers. Soc. Psychol. Bull. 31:991-1004

Hogg MA, Terry DJ. 2000. Social identity and self-categorization processes in organizational contexts. Acad. Manage. Rev. 25:121-40

Huff AS, ed. 1990. Mapping Strategic Thought. Chichester, UK: Wiley

Hutchins E. 1995. Cognition in the Wild. Cambridge, MA: MIT Press

Ilgen DR, Hollenbeck JR, Johnson M, Jundt D. 2005. Teams in organizations: from inputprocess-output models to IMOI models. Annu. Rev. Psychol. 56:517-43

Janssen O. 2004. How fairness perceptions make innovative behavior more or less stressful. $\mathcal{F}$. Organ. Behav. 25:201-15

Johnson DE, Erez A, Kiker DS, Motowidlo SJ. 2002. Liking and attributions of motives as mediators of the relationships between individuals' reputations, helpful behaviors, and raters' reward decisions. F. Appl. Psychol. 87:808-15

Johnson DR, Hoopes DG. 2003. Managerial cognition, sunk costs and the evolution of industry structure. Strat. Manage. F. 24:1057-58

Johnson-Laird PN. 1983. Mental Models: Towards a Cognitive Science of Language, Inference, and Consciousness. Cambridge, MA: Cambridge Univ. Press

Jones DG, Endsley MR. 2000. Overcoming representational errors in complex environments. Hum. Factors 42:367-78

Judge TA, Bono JE. 2001. Relationship of core self-evaluations traits-self-esteem, generalized self-efficacy, locus of control, and emotional stability—with job satisfaction and job performance: a meta-analysis. F. Appl. Psychol. 86:80-92

Judge TA, Colbert AE, Ilies R. 2004a. Intelligence and leadership: a quantitative review and test of theoretical propositions. F. Appl. Psychol. 89:542-52

Judge TA, Jackson CL, Shaw JC, Scott BA, Rich BL. 2007. Self-efficacy and work-related performance: the integral role of individual differences. F. Appl. Psychol. 92:107-27

Judge TA, Van Vianen AEM, De Pater IE. 2004b. Emotional stability, core self-evaluations, and job outcomes: a review of the evidence and an agenda for future research. Hum. Perform. 17:325-46

Kahneman D, Tversky A. 1996. On the reality of cognitive illusions. Psychol. Rev. 103:582-91

Kark R, Shamir B, Chen G. 2003. The two faces of transformational leadership: empowerment and dependency. F. Appl. Psychol. 88:246-55

Kay AC, Wheeler SC, Bargh JA, Ross L. 2004. Material priming: the influence of mundane physical objects on situational construal and competitive behavioral choice. Organ. Behav. Hum. Decis. Process. 95:83-96

Keeping LM, Levy PE. 2000. Performance appraisal reactions: measurement, modeling, and method bias. F. Appl. Psychol. 85:708-23

Kelley HH. 1967. Attribution theory in social psychology. In Nebraska Symposium on Motivation, ed. D Levine, pp. 192-240. Lincoln, NE: Univ. Nebraska Press

Kelly JR, Barsade SG. 2001. Mood and emotions in small groups and work teams. Organ. Behav. Hum. Decis. Process. 86:99-130

Kiesler S, Sproull L. 1982. Managerial response to changing environments: perspectives on problem sensing from social cognition. Admin. Sci. Q. 27:548-70
A highly cited article that draws on the social identity approach to analyze a wide range of organizational phenomena.

Reports five pioneering laboratory experiments that demonstrate exposure to business artifacts can influence judgments and behavior without conscious awareness. 
Large-scale investigation of the cognitive effects of stress on learning, integrating insights from personality, ability, stress, motivation, and learning theories.

\section{Provides a} state-of-the-art overview of the contributions and limitations of naturalistic decision making, accompanied by 16 peer commentaries.
Kilduff M, Angelmar R, Mehra A. 2000. Top management-team diversity and firm performance: examining the role of cognitions. Organ. Sci. 11:21-34

Klein GA. 1993. A recognition-primed decision (RPD) model of rapid decision making. In Decision Making in Action: Models and Methods, ed. G Klein, J Orasanu, R Calderwood, C Zsambok, pp. 138-47. Norwood, CT: Ablex

Kozlowski SWJ, Gully SM, Brown KG, Salas E, Smith EM, Nason ER. 2001. Effects of training goals and goal orientation traits on multidimensional training outcomes and performance adaptability. Organ. Behav. Hum. Decis. Process. 85:1-31

Kraiger K, Ford JK, Salas E. 1993. Application of cognitive, skill-based and affective theories of learning outcomes to new methods of training evaluation. 7. Appl. Psychol. 78:311-28

Kuvaas B, Selart M. 2004. Effects of attribute framing on cognitive processing and evaluation. Organ. Behav. Hum. Decis. Process. 95:198-207

Labianca G, Gray B, Brass DJ. 2000. A grounded model of organizational schema change during empowerment. Organ. Sci. 11:235-57

Lane PJ, Koka BR, Pathak S. 2006. The reification of absorptive capacity: a critical review and rejuvenation of the construct. Acad. Manage. Rev. 31:833-63

Langan-Fox J, Code S, Langfield-Smith K. 2000. Team mental models: techniques, methods, and analytic approaches. Hum. Factors 42:242-71

Lant TK, Shapira Z. 2001. New research directions on organizational cognition. In Managerial and Organizational Cognition: Computation and Interpretation, ed. TK Lant, Z Shapira, pp. 367-76. Mahwah, NJ: Erlbaum

Latham GP, Pinder CC. 2005. Work motivation theory and research at the dawn of the twentyfirst century. Annu. Rev. Psychol. 56:485-516

Lazarus RS, Folkman S. 1984. Stress Appraisal and Coping. New York: Springer

Leach DJ, Wall TD, Jackson PR. 2003. The effect of empowerment on job knowledge: an empirical test involving operators of complex technology. 7. Occup. Organ. Psychol. 76:2752

LePine JA. 2003. Team adaptation and postchange performance: effects of team composition in terms of members' cognitive ability and personality. 7. Appl. Psychol. 88:27-39

LePine JA. 2004. Challenge and hindrance stress: relationships with exhaustion, motivation to learn, and learning performance. F. Appl. Psychol. 89:883-91

Levesque LL, Wilson JM, Wholey DR. 2001. Cognitive divergence and shared mental models in software development project teams. 7. Organ. Behav. 22:135-44

Levin IP, Huneke ME, Jasper JD. 2000. Information processing at successive stages of decision making: need for cognition and inclusion-exclusion effects. Organ. Behav. Hum. Decis. Process. 82:171-93

Lieberman MD. 2007. Social cognitive neuroscience: a review of core processes. Anпu. Rev. Psychol. 58:259-89

Lievens F, Chasteen CS, Day EA, Christiansen ND. 2006. Large-scale investigation of the role of trait activation theory for understanding assessment center convergent and discriminant validity. 7. Appl. Psychol. 91:247-58

Lim BC, Klein KJ. 2006. Team mental models and team performance: a field study of the effects of team mental model similarity and accuracy. F. Organ. Behav. 27:403-18

Lipshitz R, Cohen MS. 2005. Warrants for prescription: analytically and empirically based approaches to improving decision making. Hum. Factors 47:102-20

Lipshitz R, Klein G, Carroll JS, eds. 2006. Special issue on "naturalistic decision making and organizational decision making: exploring the intersections." Org. Stud. 27:917-1057

Lipshitz R, Klein G, Orasanu J, Salas E. 2001. Focus article: taking stock of naturalistic decision making. F. Behav. Decis. Mak. 14:331-52 
Locke EA, Latham GP. 2004. What should we do about motivation theory? Six recommendations for the twenty-first century. Acad. Manage. Rev. 29:388-403

London M, Mone EM, Scott JC. 2004. Performance management and assessment: methods for improved rater accuracy and employee goal setting. Hum. Resour. Manage. 43:319-36

Lord RG, Brown DJ, Harvey JL, Hall RJ. 2001. Contextual constraints on prototype generation and their multilevel consequences for leadership perceptions. Leadersh. Q. 12:311-38

Lord RG, Emrich CG. 2000. Thinking outside the box by looking inside the box: extending the cognitive revolution in leadership research. Leadersh. Q. 11:551-79

Lord RG, Foti RJ, Devader CL. 1984. A test of leadership categorization theory: internal structure, information-processing, and leadership perceptions. Organ. Behav. Hum. Perform. 34:343-78

Lord RG, Hall RJ. 2005. Identity, deep structure and the development of leadership skill. Leadersh. Q. 16:591-615

Lord RG, Maher KJ. 1991. Leadership and Information Processing: Linking Perception and Performance. Boston, MA: Unwin Hyman

Lowe R, Bennett P. 2003. Exploring coping reactions to work-stress: application of an appraisal theory. 7. Occup. Organ. Psychol. 76:393-400

Maitlis S. 2005. The social processes of organizational sensemaking. Acad. Manage. 7. 48:21-49

Maitlis S, Ozcelik H. 2004. Toxic decision processes: a study of emotion and organizational decision making. Organ. Sci. 15:375-93

Malhotra A, Majchrzak A, Carman R, Lott V. 2001. Radical innovation without collocation: a case study at Boeing-Rocketdyne. MIS Q. 25:229-49

March JG, Simon HA. 1958. Organizations. New York: Wiley

Markoczy L. 1997. Measuring beliefs: accept no substitutes. Acad. Manage. 7. 40:1228-42

Markoczy L. 2001. Consensus formation during strategic change. Strat. Manage. F. 22:1013-31

Marks MA, DeChurch LA, Mathieu JE, Panzer FJ, Alonso A. 2005. Teamwork in multiteam systems. 7. Appl. Psychol. 90:964-71

Marks MA, Sabella MJ, Burke CS, Zaccaro SJ. 2002. The impact of cross-training on team effectiveness. 7. Appl. Psychol. 87:3-13

Martell RF, Evans DP. 2005. Source-monitoring training: toward reducing rater expectancy effects in behavioral measurement. F. Appl. Psychol. 90:956-63

Martinko MJ, Gundlach MJ, Douglas SC. 2002. Toward an integrative theory of counterproductive workplace behavior: a causal reasoning perspective. Int. F. Sel. Assess. 10:36-50

Maslach C, Schaufeli WB, Leiter MP. 2001. Job burnout. Annu. Rev. Psychol. 52:397-422

Mathieu JE, Heffner TS, Goodwin GF, Cannon-Bowers JA, Salas E. 2005. Scaling the quality of teammates' mental models: equifinality and normative comparisons. F. Organ. Behav. 26:37-56

Mathieu JE, Heffner TS, Goodwin GF, Salas E, Cannon-Bowers JA. 2000. The influence of shared mental models on team process and performance. F. Appl. Psychol. 85:273-83

Mathieu JE, Marks MA, Zaccaro SJ. 2001. Multiteam systems. In Handbook of Industrial, Work and Organizational Psychology: Volume 2-Organizational Psychology, ed. N Anderson, DS Ones, HK Sinangil, C Viswesvaran, pp. 289-331. London: Sage

McNamara G, Luce RA, Tompson GH. 2002. Examining the effect of complexity in strategic group knowledge structures on firm performance. Strat. Manage. F. 23:153-70

Meyer JP, Becker TE, Vandenberghe C. 2004. Employee commitment and motivation: a conceptual analysis and integrative model. 7. Appl. Psychol. 89:991-1007

Mintzberg H, Waters JA. 1985. Of strategies, deliberate and emergent. Strat. Manage. 7. 6:25772
Builds on advances in connectionist modeling to account for stability and flexibility in leadership prototypes.
Advances the multiteam systems concept, applying and extending principles of shared cognition from conventional teams to "teams of teams." 
Moore JE. 2000. Why is this happening? A causal attribution approach to work exhaustion consequences. Acad. Manage. Rev. 25:335-49

Morgeson FP, Humphrey SE. 2006. The Work Design Questionnaire (WDQ): developing and validating a comprehensive measure for assessing job design and the nature of work. 7. Appl. Psychol. 91:1321-39

Narayanan VK, Armstrong DJ, eds. 2005. Causal Mapping for Research in Information Technology. Hershey, PA: Idea Group Inc.

Neale MA, Tenbrunsel AE, Galvin T, Bazerman MH. 2006. A decision perspective on organizations: social cognition, behavioural decision theory and the psychological links to micro- and macro-organizational behaviour. In The Sage Handbook of Organization Studies, ed. SR Clegg, C Hardy, TB Lawrence, WR Nord, pp. 485-519. London: Sage

Nemanick RC, Clark EM. 2002. The differential effects of extracurricular activities on attributions in resume evaluation. Int. F. Sel. Assess. 10:206-17

Newell BR, Weston NJ, Shanks DR. 2003. Empirical tests of a fast-and-frugal heuristic: not everyone "takes-the-best." Organ. Behav. Hum. Decis. Process. 91:82-96

$\mathrm{Ng}$ TWH, Sorensen KL, Eby LT. 2006. Locus of control at work: a meta-analysis. F. Organ. Behav. 27:1057-87

Osborne JD, Stubbart CI, Ramaprasad A. 2001. Strategic groups and competitive enactment: a study of dynamic relationships between mental models and performance. Strat. Manage. 7. $22: 435-54$

Parasuraman R. 2000. Designing automation for human use: empirical studies and quantitative models. Ergonomics 43:931-51

Parker AM, Fischhoff B. 2005. Decision-making competence: external validation through an individual-differences approach. F. Behav. Decis. Mak. 18:1-27

Parker SK, Wall TD, Cordery JL. 2001. Future work design research and practice: towards an elaborated model of work design. 7. Occup. Organ. Psychol. 74:413-40

Patrick J, James N. 2004. Process tracing of complex cognitive work tasks. F. Occup. Organ. Psychol. 77:259-80

Perrewe PL, Zellars KL. 1999. An examination of attributions and emotions in the transactional approach to the organizational stress process. F. Organ. Behav. 20:739-52

Perrin BM, Barnett BJ, Walrath L, Grossman JD. 2001. Information order and outcome framing: an assessment of judgment bias in a naturalistic decision-making context. Hum. Factors 43:227-38

Phelps EA. 2006. Emotion and cognition: insights from studies of the human amygdala. Annu. Rev. Psychol. 57:27-53

Pierro A, Cicero L, Bonaiuto M, van Knippenberg D, Kruglanski AW. 2005. Leader group prototypicality and leadership effectiveness: the moderating role of need for cognitive closure. Leadersh. Q. 16:503-16

Ployhart RE, Harold CM. 2004. The applicant attribution-reaction theory (AART): an integrative theory of applicant attributional processing. Int. F. Sel. Assess. 12:84-98

Porac JF, Thomas H, Wilson F, Paton D, Kanfer A. 1995. Rivalry and the industry model of Scottish knitwear producers. Admin. Sci. Q. 40:203-27

Pratt MG. 2000. The good, the bad, and the ambivalent: managing identification among Amway distributors. Admin. Sci. Q. 45:456-93

Reger RK, Gustafson LT, Demarie SM, Mullane JV. 1994. Reframing the organization: why implementing total quality is easier said than done. Acad. Manage. Rev. 19:565-84

Remington RW, Johnston JC, Ruthruff E, Gold M, Romera M. 2000. Visual search in complex displays: factors affecting conflict detection by air traffic controllers. Hum. Factors 42:34966 
Ren YQ, Carley KM, Argote L. 2006. The contingent effects of transactive memory: When is it more beneficial to know what others know? Manage. Sci. 52:671-82

Rentsch JR, Klimoski RJ. 2001. Why do "great minds" think alike? Antecedents of team member schema agreement. F. Organ. Behav. 22:107-20

Repenning NP, Sterman JD. 2002. Capability traps and self-confirming attribution errors in the dynamics of process improvement. Admin. Sci. Q. 47:265-95

Rinkus S, Walji M, Johnson-Throop KA, Malin J, Turley JP, et al. 2005. Human-centered design of a distributed knowledge management system. F. Biomed. Inform. 38:4-17

Roth EM, Multer J, Raslear T. 2006. Shared situation awareness as a contributor to high reliability performance in railroad operations. Org. Stud. 27:967-87

Rouse WB, Morris NM. 1986. On looking into the black box: prospects and limits in the search for mental models. Psychol. Bull. 100:349-63

Rousseau DM. 1995. Psychological Contracts in Organizations: Understanding Written and Unwritten Agreements. Thousand Oaks, CA: Sage

Rousseau DM. 2001. Schema, promise and mutuality: the building blocks of the psychological contract. 7. Occup. Organ. Psychol. 74:511-41

Russo JE, Meloy MG, Wilks TJ. 2000. Predecisional distortion of information by auditors and salespersons. Manage. Sci. 46:13-27

Ryan AM, Ployhart RE. 2000. Applicants' perceptions of selection procedures and decisions: a critical review and agenda for the future. 7. Manage. 26:565-606

Rynes SL, Gerhart B, Parks L. 2005. Personnel psychology: performance evaluation and pay for performance. Annu. Rev. Psychol. 56:571-600

Salas E, Cannon-Bowers JA. 2001. The science of training: a decade of progress. Annu. Rev. Psychol. 52:471-99

Salgado JF, Anderson N, Moscoso S, Bertua C, De Fruyt F. 2003. International validity generalization of GMA and cognitive abilities: a European community meta-analysis. Pers. Psychol. 56:573-605

Salvendy G, ed. 2006. Handbook of Human Factors and Ergonomics. Hoboken, NJ: Wiley

Sauer J, Felsing T, Franke H, Ruttinger B. 2006. Cognitive diversity and team performance in a complex multiple task environment. Ergonomics 49:934-54

Sauer J, Hockey GRJ, Wastell DG. 2000. Effects of training on short- and long-term skill retention in a complex multiple-task environment. Ergonomics 43:2043-64

Schaubroeck J. 1999. Should the subjective be the objective? On studying mental processes, coping behavior, and actual exposures in organizational stress research. F. Organ. Behav. 20:753-60

Schmidt AM, Ford JK. 2003. Learning within a learner control training environment: the interactive effects of goal orientation and meta-cognitive instruction on learning outcomes. Pers. Psychol. 56:405-29

Schraagen JMC, Chipman SF, Shalin VL, eds. 2000. Cognitive Task Analysis. Mahwah, NJ: Erlbaum

Schroth HA, Shah PP. 2000. Procedures: Do we really want to know them? An examination of the effects of procedural justice on self-esteem. F. Appl. Psychol. 85:462-71

Shaw JC, Wild E, Colquitt JA. 2003. To justify or excuse? A meta-analytic review of the effects of explanations. 7. Appl. Psychol. 88:444-58

Silvester J, Anderson-Gough FM, Anderson NR, Mohamed AR. 2002. Locus of control, attributions and impression management in the selection interview. F. Occup. Organ. Psychol. 75:59-76

Silvester J, Patterson F, Ferguson E. 2003. Comparing two attributional models of job performance in retail sales: a field study. F. Occup. Organ. Psychol. 76:115-32 
Demonstrates how shared cognition helps control room operatives adapt to crises in a nuclear power plant.
Simon HA. 1947. Administrative Behavior. New York: Macmillan

Sitzmann T, Kraiger K, Stewart D, Wisher R. 2006. The comparative effectiveness of webbased and classroom instruction: a meta-analysis. Pers. Psychol. 59:623-64

Sloman SA, Hagmayer Y. 2006. The causal psycho-logic of choice. Trends Cogn. Sci. 10:407-12 Smith-Jentsch KA, Campbell GE, Milanovich DM, Reynolds AM. 2001. Measuring teamwork mental models to support training needs assessment, development, and evaluation: two empirical studies. F. Organ. Behav. 22:179-94

Sohn YW, Doane SM. 2004. Memory processes of flight situation awareness: interactive roles of working memory capacity, long-term working memory, and expertise. Hum. Factors 46:461-75

Srivastava A, Bartol KM, Locke EA. 2006. Empowering leadership in management teams: effects on knowledge sharing, efficacy, and performance. Acad. Manage. 7. 49:1239-51

Stajkovic AD. 2006. Development of a core confidence-higher order construct. F. Appl. Psychol. 91:1208-24

Stajkovic AD, Locke EA, Blair ES. 2006. A first examination of the relationships between primed subconscious goals, assigned conscious goals, and task performance. F. Appl. Psychol. 91:1172-80

Steel P, Konig CJ. 2006. Integrating theories of motivation. Acad. Manage. Rev. 31:889-913

Sutcliffe KM, Weick K. 2008. Information overload revisited. In The Oxford Handbook of Organizational Decision Making, ed. GP Hodgkinson, WH Starbuck, pp. 56-75. Oxford, UK: Oxford Univ. Press

Tajfel H, Turner JC. 1979. An integrative theory of intergroup conflict. In The Social Psychology of Intergroup Relations, ed. WG Austin, S Worchel, pp. 33-47. Monterey, CA: Brooks-Cole

Tasa K, Taggar S, Seijts GH. 2007. The development of collective efficacy in teams: a multilevel and longitudinal perspective. F. Appl. Psychol. 92:17-27

Tetlock PE. 2000. Cognitive biases and organizational correctives: Do both disease and cure depend on the politics of the beholder? Admin. Sci. Q. 45:293-326

Troup C, Dewe P. 2002. Exploring the nature of control and its role in the appraisal of workplace stress. Work Stress 16:335-55

Truxillo DM, Bauer TN, Campion MA, Paronto ME. 2002. Selection fairness information and applicant reactions: a longitudinal field study. F. Appl. Psychol. 87:1020-31

Tversky A, Kahneman D. 1974. Judgment under uncertainty: heuristics and biases. Science 185:1124-31

van Knippenberg B, van Knippenberg D. 2005. Leader self-sacrifice and leadership effectiveness: the moderating role of leader prototypicality. F. Appl. Psychol. 90:25-37

van Knippenberg D, Schippers MC. 2007. Work group diversity. Annu. Rev. Psychol. 58:515-41

van Knippenberg D, van Knippenberg B, De Cremer D, Hogg MA. 2004. Leadership, self, and identity: a review and research agenda. Leadersh. Q. 15:825-56

Vancouver JB. 2005. The depth of history and explanation as benefit and bane for psychological control theories. F. Appl. Psychol. 90:38-52

Vancouver JB, Thompson CM, Tischner EC, Putka DJ. 2002. Two studies examining the negative effect of self-efficacy on performance. F. Appl. Psychol. 87:506-16

Wallace JC, Chen G. 2005. Development and validation of a work-specific measure of cognitive failure: implications for occupational safety. 7. Occup. Organ. Psychol. 78:615-32

Waller MJ, Gupta N, Giambatista RC. 2004. Effects of adaptive behaviors and shared mental models on control crew performance. Manage. Sci. 50:1534-44

Walsh JP. 1995. Managerial and organizational cognition: notes from a trip down memory lane. Organ. Sci. 6:280-321 
Walsh JP, Ungson GR. 1991. Organizational memory. Acad. Manage. Rev. 16:57-91

Wanberg CR, Banas JT. 2000. Predictors and outcomes of openness to changes in a reorganizing workplace. 7. Appl. Psychol. 85:132-42

Warr P. 2006. Differential activation of judgments in employee well-being. 7. Occup. Organ. Psychol. 79:225-44

Weick KE. 1979. The Social Psychology of Organizing. New York: McGraw-Hill. 2nd ed.

Weick KE, Quinn RE. 1999. Organizational change and development. Annu. Rev. Psychol. 50:361-86

Wickens CD, Carswell CM. 2006. Information processing. In Handbook of Human Factors and Ergonomics, ed. G Salvendy, pp. 111-49. Hoboken, NJ: Wiley

Wiggins MW, Bollwerk S. 2006. Heuristic-based information acquisition and decision making among pilots. Hum. Factors 48:734-46

Wong KF, Yik M, Kwong JYY. 2006. Understanding the emotional aspects of escalation of commitment: the role of negative affect. F. Appl. Psychol. 91:282-97

Wood RE, Bandura A. 1989. Social-cognitive theory of organizational management. Acad. Manage. Rev. 14:361-84

Wright G, Goodwin P. 2002. Eliminating a framing bias by using simple instructions to "think harder" and respondents with managerial experience: comment on "Breaking the Frame." Strat. Manage. F. 23:1059-67

Wright RP. 2004. Mapping cognitions to better understand attitudinal and behavioral responses in appraisal research. 7. Organ. Behav. 25:339-74

Yeo GB, Neal A. 2006. An examination of the dynamic relationship between self-efficacy and performance across levels of analysis and levels of specificity. F. Appl. Psychol. 91:1088-101

Zhang JJ, Norman DA. 1994. Representations in distributed cognitive tasks. Cogn. Sci. 18:87122

Zhang JJ, Patel VL, Johnson KA, Smith JW, Malin J. 2002. Designing human-centered distributed information systems. IEEE Intell. Syst. 17:42-47 
象

\section{Contents}

Annual Review of

Psychology

Volume 59, 2008

\section{Prefatory}

The Evolution of a Cognitive Psychologist: A Journey from Simple Behaviors to Complex Mental Acts Gordon H. Bower

\section{Pharmacology and Behavior}

Addiction and the Brain Antireward System

George F. Koob and Michel Le Moal.

\section{Consummatory Behavior}

The Brain, Appetite, and Obesity

Hans-Rudolf Berthoud and Christopher Morrison 55

Sex

Neuroendocrine Regulation of Feminine Sexual Behavior: Lessons from Rodent Models and Thoughts About Humans Feffrey D. Blaustein 93

\section{Audition and Its Biological Bases}

The Biological Basis of Audition

Gregg H. Recanzone and Mitchell L. Sutter

\section{Color Perception}

Color in Complex Scenes

Steven K. Shevell and Frederick A.A. Kingdom

\section{Scene Perception, Event Perception, or Object Recognition}

Visual Perception and the Statistical Properties of Natural Scenes 


\section{Cognitive Processes}

The Mind and Brain of Short-Term Memory

John Jonides, Richard L. Lewis, Derek Evan Nee, Cindy A. Lustig,

Marc G. Berman, and Katherine Sledge Moore

\section{Memory}

Relativity of Remembering: Why the Laws of Memory Vanished

Henry L. Roediger, III

\section{Reasoning and Problem Solving}

Dual-Processing Accounts of Reasoning, Judgment, and Social Cognition Fonathan St. B.T. Evans

\section{Comparative Psychology, Ethology, and Evolution}

Putting the Altruism Back into Altruism: The Evolution of Empathy

Frans B.M. de Waal

\section{Anxiety Disorders}

Social Bonds and Posttraumatic Stress Disorder Anthony Charuvastra and Marylène Cloitre

\section{Inference, Person Perception, Attribution}

Spontaneous Inferences, Implicit Impressions, and Implicit Theories fames S. Uleman, S. Adil Saribay, and Celia M. Gonzalez

\section{Social Development, Social Personality, Social Motivation, Social Emotion}

Motives of the Human Animal: Comprehending, Managing, and Sharing Inner States

E. Tory Higgins and Thane S. Pittman

\section{Cognition in Organizations}

Cognition in Organizations Gerard P. Hodgkinson and Mark P. Healey

\section{Selection and Placement}

Personnel Selection

Paul R. Sackett and Filip Lievens 


\section{Education of Special Populations}

The Education of Dyslexic Children from Childhood to Young Adulthood Sally E. Shayzitz, Robin Morris, and Bennett A. Shaywitz ...

\section{Health Promotion and Disease Prevention}

Health Psychology: The Search for Pathways Between Behavior and Health

Howard Leventhal, Fohn Weinman, Elaine A. Leventhal, and L. Alison Phillips ....477

\section{Emotion}

Human Abilities: Emotional Intelligence

Fobn D. Mayer, Richard D. Roberts, and Sigal G. Barsade

\section{Data Analysis}

Sample Size Planning for Statistical Power and Accuracy in Parameter Estimation Scott E. Maxwell, Ken Kelley, and Joseph R. Rausch

\section{Timely Topics}

A Comprehensive Review of the Placebo Effect: Recent Advances and Current Thought Donald D. Price, Damien G. Finniss, and Fabrizio Benedetti 565

Children's Social Competence in Cultural Context Xinyin Chen and Doran C. French

Grounded Cognition Lawrence W. Barsalou

Neuroeconomics

George Loewenstein, Scott Rick, and Fonathan D. Cohen .647

\section{Indexes}

Cumulative Index of Contributing Authors, Volumes 49-59 .673

Cumulative Index of Chapter Titles, Volumes 49-59 678

\section{Errata}

An online log of corrections to Annual Review of Psychology articles may be found at http://psych.annualreviews.org/errata.shtml 